\title{
Neurobehavioural effects of Vigna unguiculata spp Dekindtiana (L.) Walp in mice
}

\section{Adekunle Theophilus ADEGBUYI ${ }^{1 *}$, Moses Atanda AKANMU ${ }^{1}$ and Gbola OLAYIWOLA ${ }^{2}$}

\author{
1Deparment of Pharmacology and Therapeutics, Faculty of Basic Clinical Sciences, College of Medicine, Ekiti-State \\ University, Ado Ekiti, Nigeria. \\ ${ }^{2}$ Department of Pharmacology, Faculty of Pharmacy, Obafemi Awolowo University, Ile-Ife. Nigeria. \\ *Corresponding author Email: adekunlegbuyi@googlemail.com
}

\begin{abstract}
Copyright @ 2019 Adegbuyi et al. This article remains permanently open access under the terms of the Creative Commons Attribution License 4.0, which permits unrestricted use, distribution, and reproduction in any medium, provided the original work is properly cited.
\end{abstract}

Received 11th June, 2019; Accepted 9th July, 2019

\begin{abstract}
S: The study investigated the pharmacological effects of the extract and fractions of Vigna unguiculata spp dekindtiana. The neurobehavioural parameters investigated in this study include: rearing, grooming and locomotion as well as pentobarbital-induced sleeping time model as a measure of the sedative effect of the plant. The neuropharmacological profile of the plant was determined in mice. The extract and fractions were administered orally at doses of $100,200,400$ and $800 \mathrm{mg} / \mathrm{kg}$ for novelty-induced behavior while phenobarbital-induced sleeping time was assessed at the doses of 100,200 and $400 \mathrm{mg} / \mathrm{kg}$. The result obtained showed significant decrease in rearing, grooming and locomotion with increase in the dose of the extract and the fractions indicating the central inhibitory effect of the plant extract. The possible mechanism of action of the novelty-induced behaviours was investigated by using picrotoxin (GABA antagonist), cyproheptadine ( $5 \mathrm{HT}_{2}$ antagonist), yohimbine (alpha 2 adrenergic antagonist). The result of the study showed the reversal of the novelty-induced rearing and locomotion with picrotoxin while the reduction in novelty-induced behaviour (rearing and locomotion) was potentiated by both cyproheptadine and yohimbine. This shows the possibility of GABAergic, serotonergic and adrenergic involvement in the behavioural effects of the extract and its fractions. Also, the methanol extract and ethyl acetate fraction showed dose-dependent increase in sleeping time and dose-dependent decrease in sleep latency indicating the hypnotic effect of the extract of the plant. The possible mechanism of action of the phenobarbital-induced sleeping time was investigated using flumazenil (an antagonist of GABA), where a reversal was obtained suggesting the possible involvement of GABAergic receptor. In conclusion, the result showed that methanol extract and its fractions exhibited both central inhibitory effect and hypnotic effect in mice.
\end{abstract}

Keyword: Grooming, locomotion, novelty-induced behavior, phenobarbital-induced sleeping time, rearing, Vigna unguiculata spp dekindtiana.

\section{INTRODUCTION}

The plant Vigna unguiculata subspecies dekindtiana is wild leguminous plant growing in tropical and semi-arid tropics covering Asia, Africa and Europe (Gangarao et al., 2007). Like other cowpeas, they are drought-tolerant and warm-weather plant crops and are well adapted to dry regions of the tropics (Ishyaku and Aliyu, 2013). They have ability to fix atmospheric nitrogen via its root noodles (Ayan et al., 2012). It is a herbaceous vine that has trailing twining branches that can grow up to two meters or more in length and it is a member of papillonaceae subfamily of the fabaceae family (Gangarao et al., 2007). Flowers of wild and cultivated cowpea are identical, but the pods and seeds are much smaller. Unlike cultivated cowpea, seeds of wild cowpea have some dormancy and ripe pods shatter their seeds (Lush et al., 1980). The plant has been shown to have a forage potential (Ayan et al., 2012). Traditionally, the decoction of the aerial parts of the plant (leaves and stem) has been reported to possess some central nervous effects such as anticonvulsant and analgesic effects (Aduema et al., 2017). The roasted seed of the cultivated 
species $V$. unguiculata has been used traditionally to manage insomnia, weakness of memory and dyspepsia (Gupta et al, 2016). Leaves of wild and cultivated cowpea are often cooked as a nutritious leafy vegetable (Fery, 2002; Singh et al., 2003). The antidepressant effect of $V$. unguiculata subspecies dekindtina has been reported (Akinpelu et al., 2017). Insomnia is defined as a repeated difficulty with sleep initiation, maintenance, consolidation or quality with higher prevalence among the seniors. Most drugs that are in use clinically to manage insomnia come with serious side effects. Therefore, there is need for continuous search for new agents that is more effective and with fewer side effects. The decoction of the aerial part (leave and stem) of the plant is used locally in Western part of Nigeria to manage pain, insomnia, fever, convulsion and headache especially migraine and other neurobehavioural disorders (Akinpelu et al., 2017). These ethno medicinal uses have not been investigated hence; this study was carried out to explore the rational for the use of the plant in the management of these neurological diseases by the local people.

\section{MATERIALS AND METHODS}

\section{Collection of plant materials and identification}

The aerial parts (leaf and stem) of $V$. unguiculata subspecies dekindtiana (wild) were collected around the Faculty of Pharmacy, Obafemi Awolowo University, Ile-Ife. The plant was identified by Mr. O. S. Shasanyan of Forestry Research Institute (FRIN), Ibadan and later authenticated by Prof. Illoh of Department of Botany of Obafemi Awolowo University, Ile-lfe, with voucher no 109763 with a specimen deposited at FRIN in Ibadan.

\section{Preparation of the plant extracts}

The plant materials were air-dried in the shade at room temperature and pulverized. The powdered material $2.9 \mathrm{~kg}$ was extracted with absolute methanol. The extract was concentrated in vacuo to yield $96 \mathrm{~g}$ crude extract (3.3\%). Sixty (60)g of the crude extract was partitioned into nhexane, ethylacetate, butanol and aqueous fractions yielding $14.4 \mathrm{~g}$ of $\mathrm{n}$-hexane $(24 \%), 2.2 \mathrm{~g}$ of ethylacetate (3.7\%), $3.6 \mathrm{~g}$ of butanol (6\%) and $23.6 \mathrm{~g}$ of aqueous fraction $(39.3 \%)$. The extract and fractions were placed in a desiccator (containing activated silica gel) until needed for experimental work. The methanol extract (VUM) and nhexane fraction (VUH), ethylacetate fraction (VUE) and butanol fraction (VUB) were solubilized with $2 \%$ tween 20 in normal saline while the aqueous fraction was dissolved in normal saline.

\section{Animals}

Swiss albino mice of both sexes were obtained from animal house of Faculty of Pharmacy, Obafemi Awolowo University lle-Ife. The animals were kept in standard cages in a well-lit animal house. The animals were fed with standard animal feed (standard pellets produced by Vital Feed, a subsidiary of UAC Foods Nigeria Limited) and maintained under natural day/night condition. The protocol for care of animals as approved by the ethical committee of the University was followed. The animals were also allowed free access to water.

\section{Drugs}

The drugs used in this experiment included: pentobarbitone sodium (M\&B, Saggital, England); diazepam (Roche, Basel, Switzerland); picrotoxin, cyproheptadine, yohimbine (Sigma Chemicals Co, St. Louis, Missouri, U.S.A.); flumazenil (Hikmal Farmaceutical, Portugal), normal saline (Unique pharmaceuticals, Lagos, Nigeria); Piracetam (Big Pharma, USA).

\section{Behavioural assays}

\section{Novelty-induced rearing, grooming and horizontal locomotion}

The method described by Ajayi and Ukponmwan (1994) and Onigbogi et al. (2000) was used to evaluate these novelty-induced behaviours. The methanol crude extract of $V$. unguiculata subspecies dekindtiana (VUM) and its fraction (n-hexane (VUH), ethyl acetate (VUE), butanol (VUB) and aqueous fraction (VUA)) were evaluated for their effect on the behaviour of mice in the open field (Stanford, 2007). The apparatus is made of rectangular wooden box measuring $(45 \mathrm{~cm} \times 25 \mathrm{~cm} \times 25 \mathrm{~cm})$ with only one side transparent (made of transparent glass) for the purpose of taking the readings of the observed behaviours. Behavioural measurements were assessed for 30 minutes after one hour of administration of vehicle $2 \%$ tween 20 in normal saline $(10 \mathrm{ml} / \mathrm{kg}$, p.o.) and graded doses of the methanol extract $(100,200,400,800 \mathrm{mg} / \mathrm{kg}$, p.o.) $(\mathrm{n}=5)$ while diazepam $2 \mathrm{mg} / \mathrm{kg}$ (p.o.) served as positive control (Aderibigbe et al., 2010; Oyekunle et al., 2010). Each animal was placed directly at the center of the observation cage after extract administration. The behavioural parameters such as rearing, grooming and locomotion were recorded for 30 minutes. Rearing frequency was taken as the number of times the mouse was standing on its hind limb or with its forelimbs leaning against the wall of the observation cage or in the free air (Ajayi and Ukponmwan, 1994). Grooming frequency was taken as the number of body cleaning with paws while horizontal locomotion is the number of squares crossed with four paws (Falodun et al., 2015). The cage was cleansed with $70 \%$ ethanol after each assessment to remove olfactory cue from the previous animal (Hershey et al., 2018). The 
experiment was carried out between 9.00 am and $4.00 \mathrm{pm}$ daily to avoid changes in biological rhythm. The same protocol was repeated for all the fractions. In another set of experiments, mice were pretreated with specific antagonists for 15 minutes prior to the administration of selected doses of the extract and fractions on noveltyinduced rearing and horizontal locomotion behaviour in mice. The antagonist used in these experiments include: picrotoxin $\left(\mathrm{GABA}_{A}\right.$ antagonist, $1.0 \mathrm{mg} / \mathrm{kg}$, i.p.), yohimbine (alpha. adrenergic antagonist, $1.0 \mathrm{mg} / \mathrm{kg}$, i.p.) and cyproheptadine (5-HT2 antagonist, $0.5 \mathrm{mg} / \mathrm{kg}$, i.p.).

\section{Pentobarbital - induced sleeping time}

The methanol extract and its fractions were evaluated for their hypnotic effect using pentobarbital- induced sleeping time (Olayiwola et al., 2013, Kumar et al., 2014). Mice were randomnised into five groups ( $n=5$ per group). The first group served as the control and was given $2 \%$ tween 20 in saline $(10 \mathrm{ml} / \mathrm{kg}$, i.p.) while groups 2 to 4 were given different doses of the methanol extract of $V$. unguiculata (100 to $400 \mathrm{mg} / \mathrm{kg}$, p.o.). The last group that served as standard control received diazepam (2 $\mathrm{mg} / \mathrm{kg}$ i.p.). Then, pentobarbital sodium (30 mg/kg i.p.) was administered after 60 minutes. The sleep latency and sleeping time were recorded. The sleep latency was measured as the time in minutes after treatment with pentobarbital that the mice experienced loss of righting reflex while the time in minute between the loss and regaining of righting reflex was taken as the sleeping time (Erden et al., 1997; Hasan et al., 2009). The protocol was repeated for various fractions of $V$. unguiculata (VUH, VUE, VUB, VUA). Flumazenil,

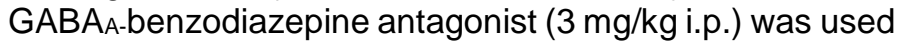
to evaluate the mechanism of hypnotic effect of extract and fractions.

\section{Statistical analysis}

Graph pad instat version 3.10 was used for the analysis of the data. Results are expressed as mean \pm SEM. The significant difference between groups was assessed using one way analysis of variance (ANOVA) followed by Student-Newman-Keuls multiple comparison test. Probability level of 0.05 was considered statistically significant.

\section{RESULTS}

Effects of extract and fractions (n-hexane, ethyl acetate, butanol and aqueous fractions) on noveltyinduced rearing in mice

The methanol extract and its fractions of $V$. unguiculata spp dekindtiana induced inhibitory effect on novelty induced rearing in mice. One way ANOVA expressed as mean \pm SEM $(n=5)$ revealed dose dependent reduction in the frequency of rearing in mice as shown in Figure 1. The inhibitory effect of the extract (VUM) was found to be significantly $(F(6,36)=34.8 p<0.05)$ different in all the groups compared to the control. The fractions VUH, VUE and VUB exhibited the same dose dependent reduction in rearing in mice (Figures 2 to 4 ) indicating the inhibitory effect of the plant. The ethyl acetate fraction (VUE) revealed a dose dependent decrease in the frequency of rearing $F(6,28)=48.2, p<0.05$ and the inhibitory effect was significantly different among the groups when compared with the control. In contrast with other fractions, the aqueous fraction (VUA) produced dose dependent increase in the novelty induced rearing in mice (Figure 5).

\section{Effect of Picrotoxin on novelty induced rearing inhibition (NIR) action of VUM and VUE}

The result in Figure 6 showed that picrotoxin reversed the inhibition of NIR induced by $100 \mathrm{mg} / \mathrm{kg}$ of both VUM and VUE.

\section{Effect of cyproheptadine on novelty induced rearing inhibition action of VUM and VUE}

The inhibitory effect on rearing activity in mice induced by $100 \mathrm{mg} / \mathrm{kg}$ of both VUM and VUE were potentiated when cyproheptadine (serotonergic antagonist) was administered 15 minutes before the extract and fraction. The difference in the inhibitory effect on rearing in mice induced by extract and fraction (Figure 7 ) were significant $(F(4,19)=17.1 ; p<0.05)$.

\section{Effect of yohimbine on novelty induced rearing inhibition effect of VUM and VUE}

Yohimbine potentiated the inhibitory effect of VUM and VUE in mice. The potentiating inhibitory rearing effect of yohimbine was significantly $(F(4,19)=28.8)$ different from the effect produced by $100 \mathrm{mg} / \mathrm{kg}$ of both VUM and VUE alone (Figure 8).

Effects of methanol extract and fractions ( $n$-hexane, ethyl acetate, butanol and aqueous fractions) on novelty induced grooming in mice

The VUM inhibited novelty-induced grooming (NIG) in mice. In the one way ANOVA, there was dose dependent reduction in the grooming activity across all doses compared to the control (Figure 9). $[F(8,36)=25.0 ; p<$ 0.05 . The reduction in grooming activity induced by $\mathrm{VUH}$ (Figure 10) and VUB $F(6,28)=10.3$ (Figure 12) were 


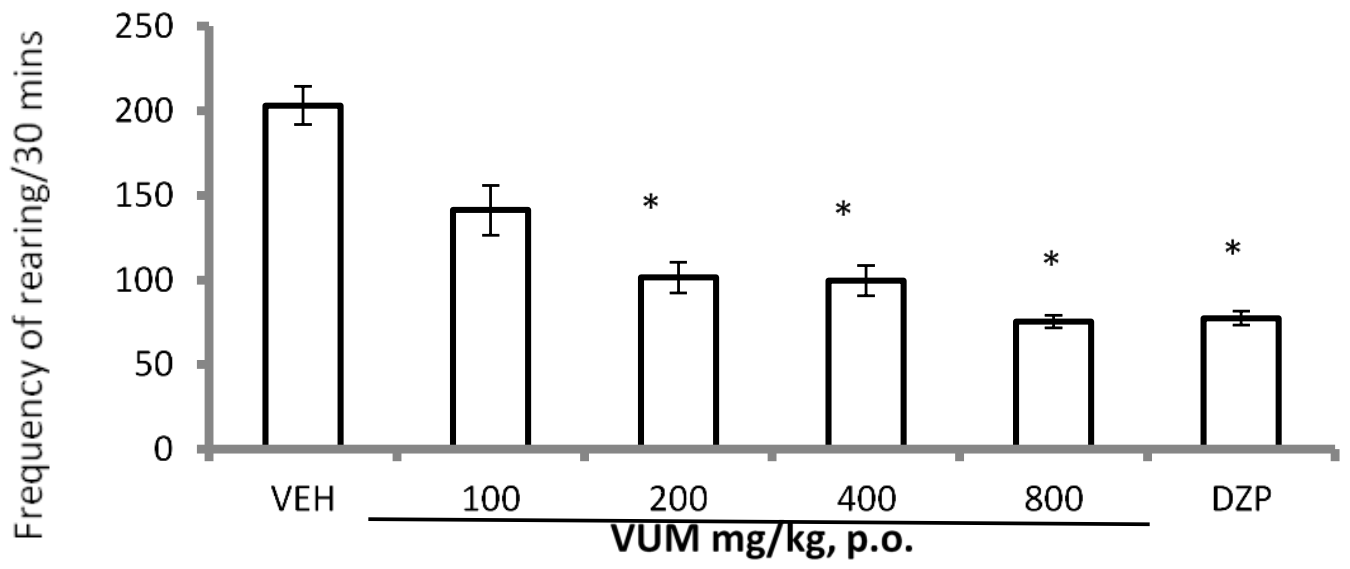

Figure 1. Effect of VUM on novelty-induced rearing. The results are expressed as mean \pm S.E.M, $(n=5)$. One way ANOVA indicated that there is significant difference between various treatment groups. DZP (2 mg/kg, p.o.), *significant $\mathrm{p}<0.05$ compared to VEH.

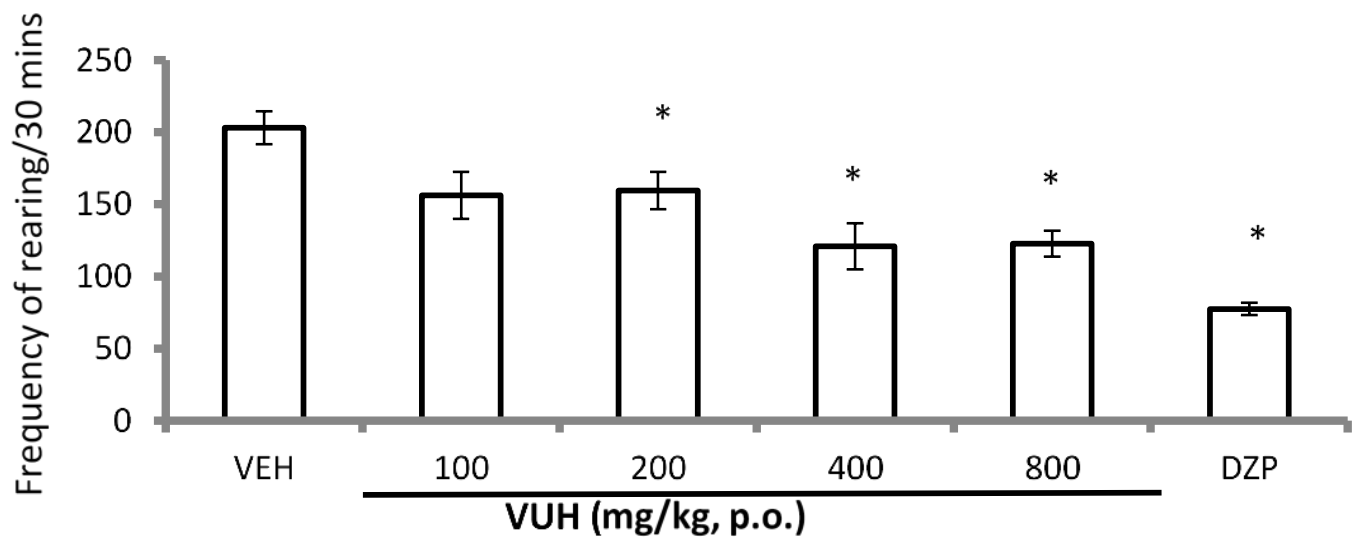

Figure 2. Effect of VUH on novelty-induced rearing. Each bar represents mean $\pm S E M(n=5)$. The result revealed dose dependent decrease in rearing activity induced by VUH. $F(6,28)=12.1$; DZP (2 mg/kg, p.o.), *significant $\mathrm{P}<0.05$ compared to $\mathrm{VEH}$.

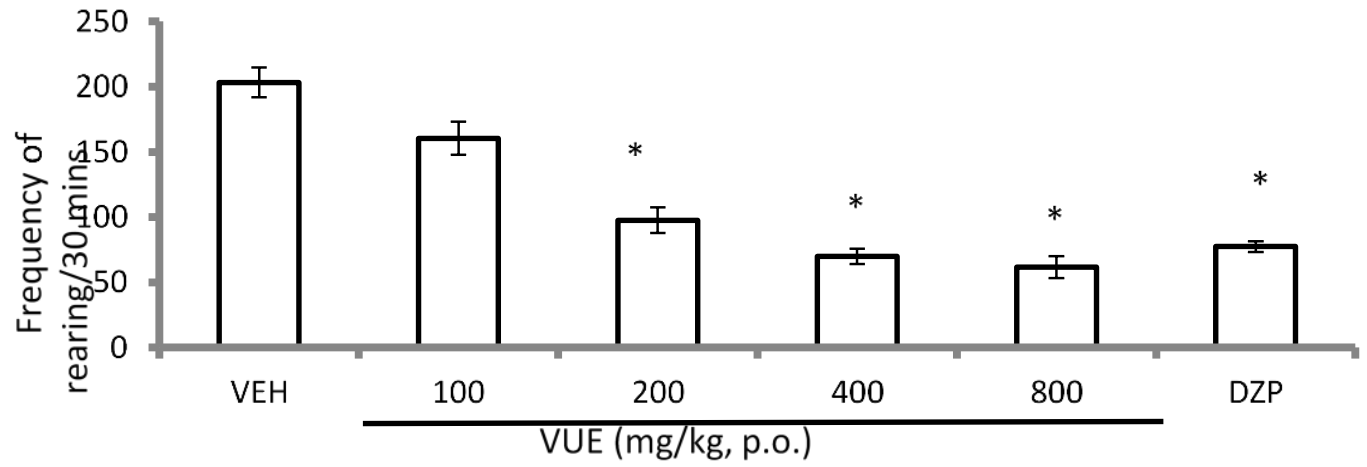

Figure 3. Effect of VUE on novelty-induced rearing. Each bar represents mean \pm SEM. VUE exerted a dose- dependent decrease in novelty induced rearing activity in mice. $\mathrm{F}(6,28)=48.2$; ${ }^{*}$ significant $\mathrm{p}<0.05$ compared to VEH. 


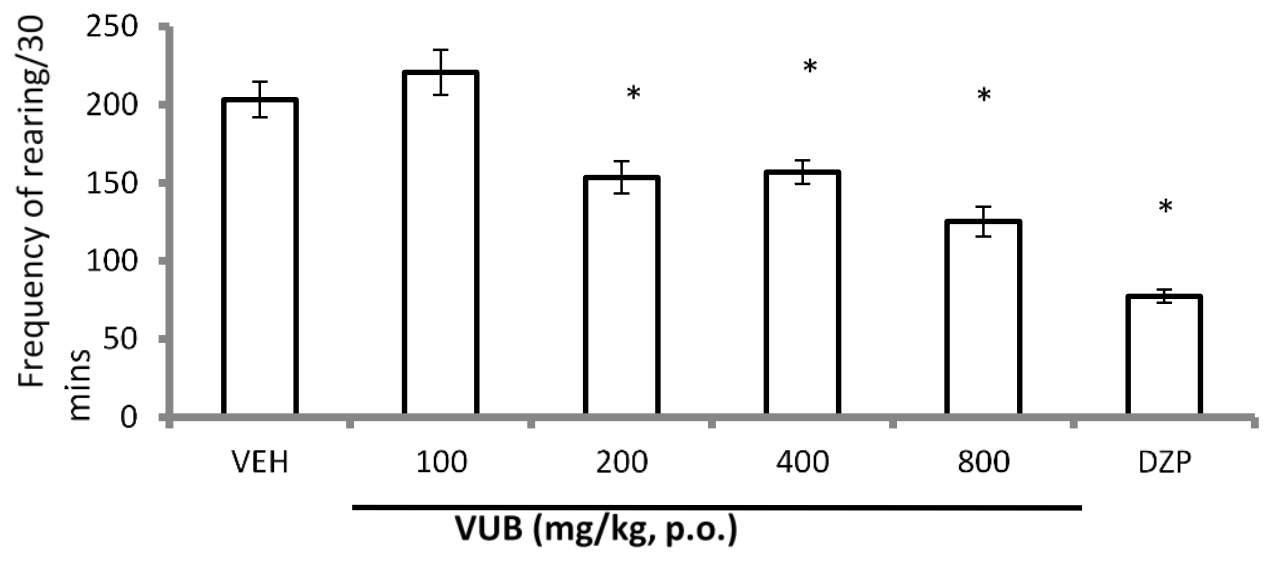

Figure 4. Effect of VUB on novelty-induced rearing. Each bar represents mean $\pm S E M$. VUB caused decease in rearing activity from 200, $400,800 \mathrm{mg} / \mathrm{kg}$ and DZP compared with VEH. $\mathrm{F}(6,28)=19.305$; *significant $\mathrm{P}<0.05$ compared to $\mathrm{VEH}$.

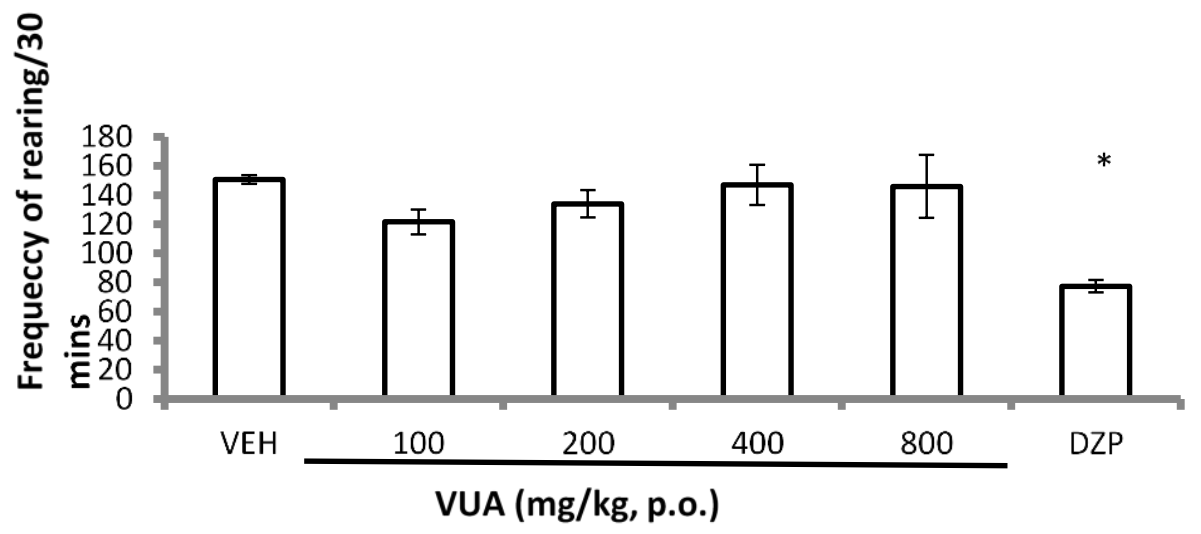

Figure 5. Effect of VUA on novelty-induced rearing. Each bar represents mean \pm SEM. One way ANOVA revealed dose dependent increase in rearing activity at all dose levels of $\operatorname{VUA~} F(6,28)=5.0$; ${ }^{*}$ significant $\mathrm{P}<0.05$ compared to $\mathrm{VEH}$.

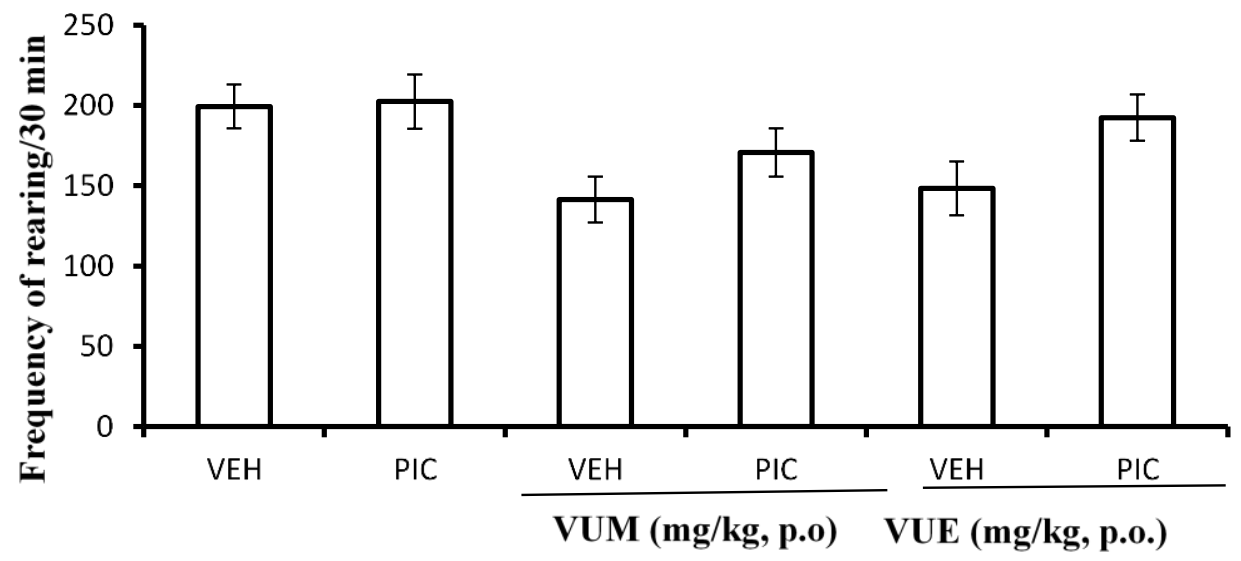

Figure 6. Effect of picrotoxin on novelty-induced rearing by VUM and VUE. Each bar represents mean \pm SEM. VUM: V. unguiculata methanol extract, (100 mg/kg, p.o.); VUE (100 $\mathrm{mg} / \mathrm{kg}$, p.o.); PIC: picrotoxin (1 mg/kg, i.p.). 


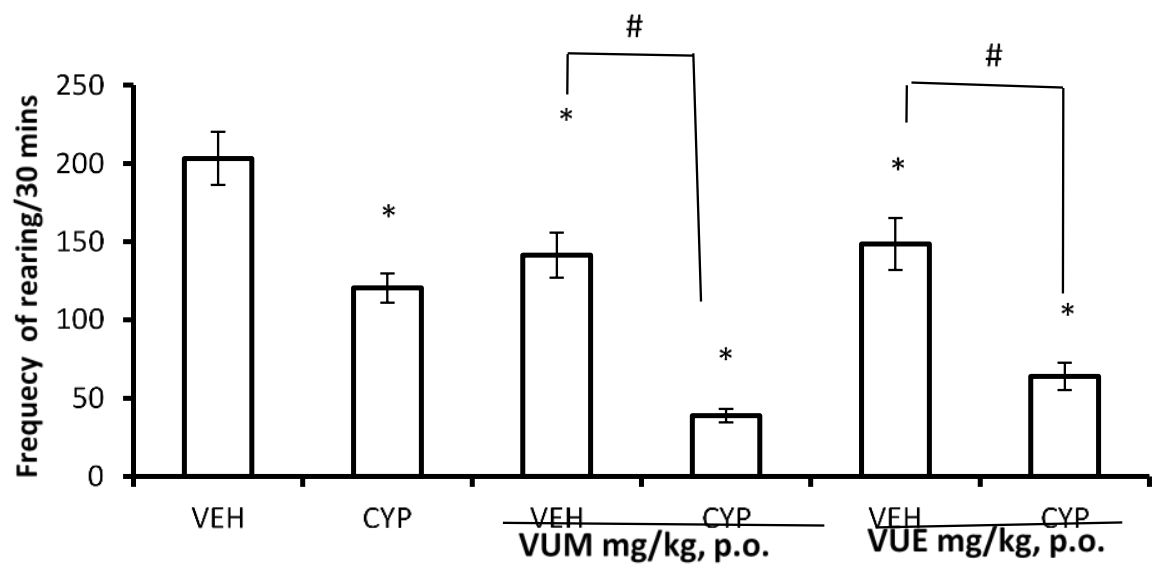

Figure 7. Effect of cyproheptadine on novelty-induced rearing by VUM and VUE. Each bar represents mean \pm SEM $(n=5)$. Cyproheptadine caused a significant decrease in rearing activity of VUM and VUE. Cyp: Cyproheptadine $\left(0.5 \mathrm{mg} / \mathrm{kg}\right.$, i.p.), ${ }^{*}$ significant $\mathrm{p}<0.05$ compared to VEH; "significant: antagonist versus treatment alone.

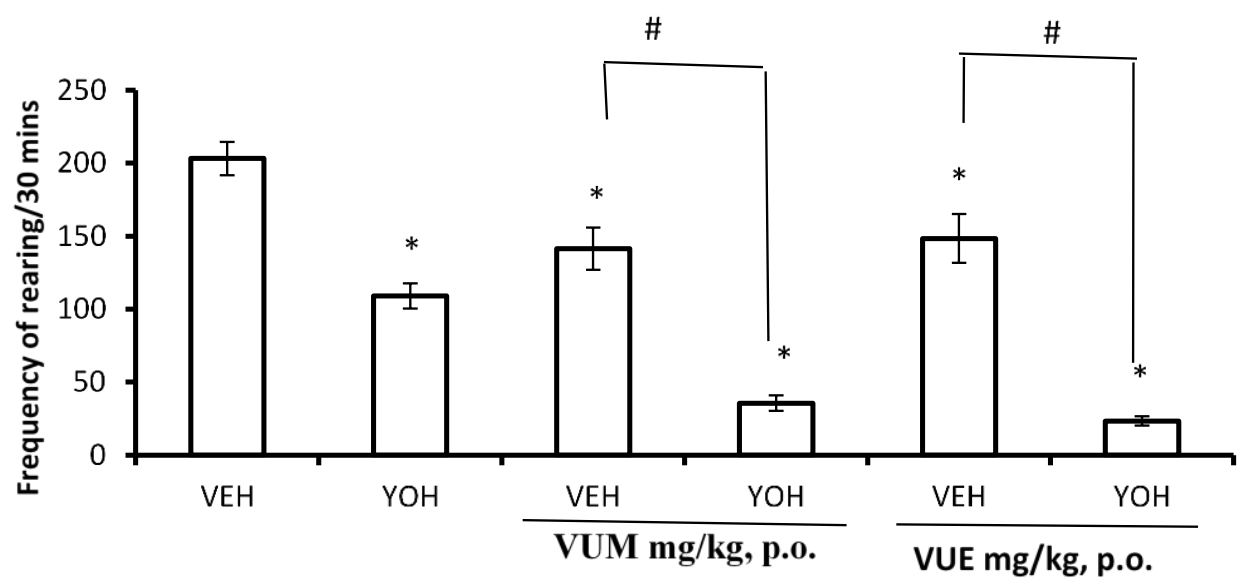

Figure 8. Effect of yohimbine on novelty-induced rearing by VUM and VUE. Each bar represents mean $\pm \operatorname{SEM}(n=5)$. Yohimbine caused a significant decrease in rearing activity of VUM (100 mg/kg, p.o.), and VUE (100 mg/kg, p.o.), YOH: Yohimbine (1 mg/kg, i.p.);

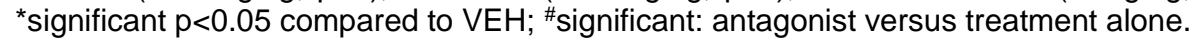

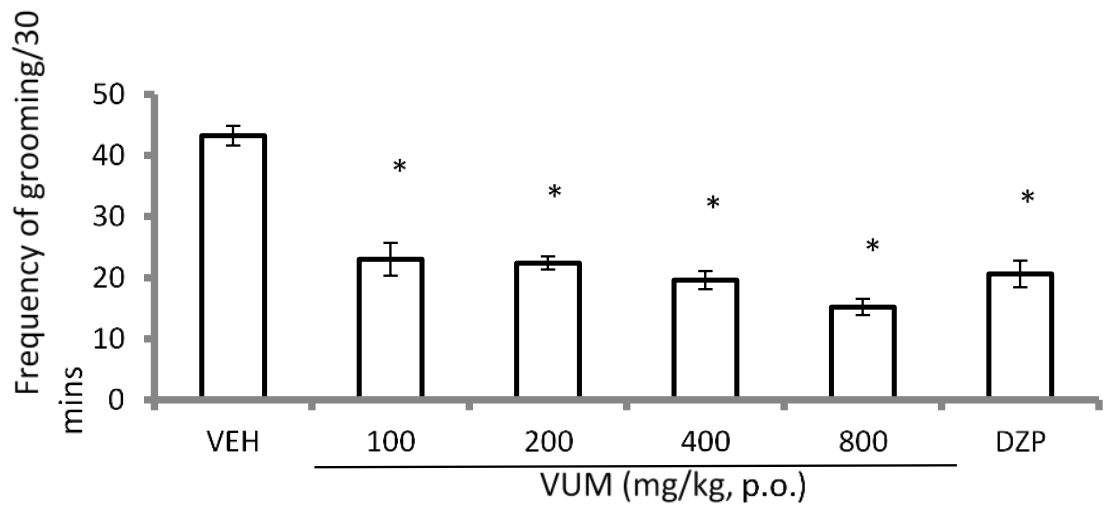

Figure 9. Effect of VUM on novelty-induced grooming. The results are expressed as mean \pm S.E.M, $(n=5)$. There is significant difference in the treatment groups compared with the VEH; *significant $p<0.05$ compared to VEH. 


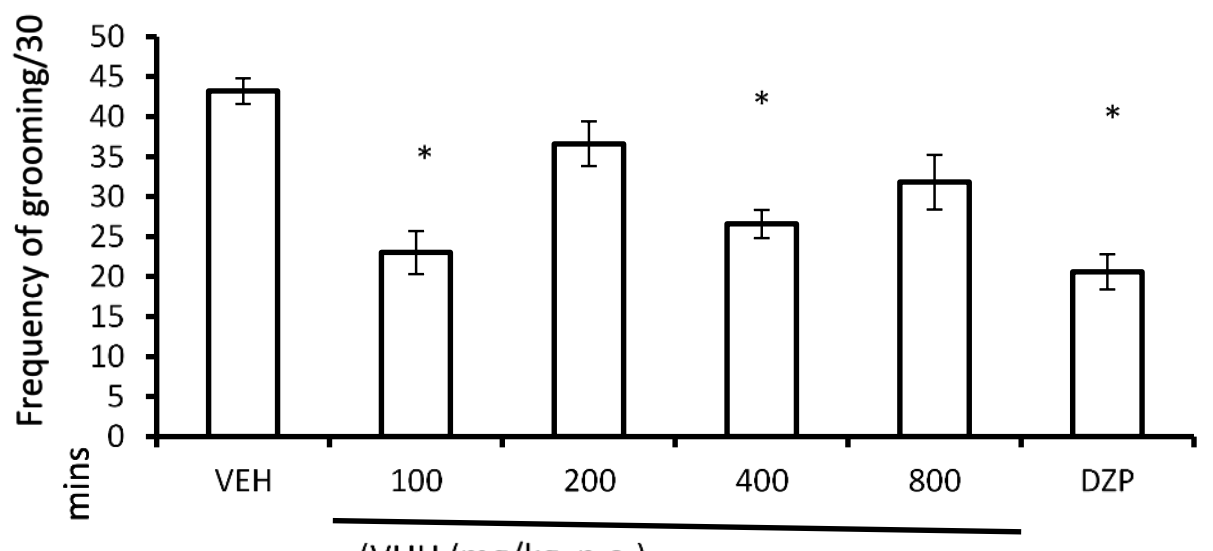

(VUH (mg/kg, p.o.)

Figure 10. Effect of VUH on novelty-induced grooming. The results are expressed as mean \pm S.E.M, $(n=5)$. *significant $p<0.05$ compared to VEH.

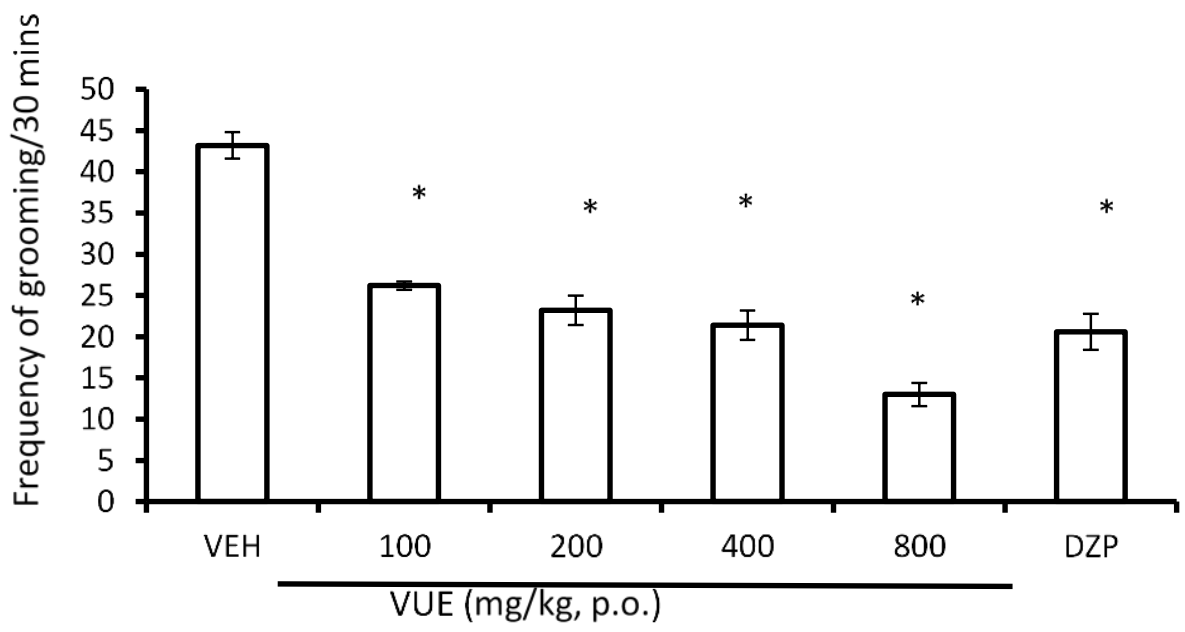

Figure 11. Effect of VUE on novelty-induced grooming. The results are expressed as mean \pm S.E.M, $(n=5)$. * significant $p<0.05$ compared to $V E H$.

dose-independent while VUE induced dose dependent decrease in grooming effect (Figure 11). On the other hand, the VUA reduced the grooming activity slightly at $(100,200$ and 800$) \mathrm{mg} / \mathrm{kg}$ while $400 \mathrm{mg} / \mathrm{kg}$ of VUA produced an increased in the grooming effect that is greater than the control (Figure 13). $F(6,28)=4.3 ; p<0.05$.

\section{Effects of methanol extract and fractions on novelty induced horizontal locomotor (NIL) activity in mice}

The methanol extract (VUM) (Figure 14) reduced the horizontal locomotor activity in mice dose dependently. The One way ANOVA revealed significant difference between all the doses of VUM and control (VEH: vehicle $10 \mathrm{ml} / \mathrm{kg}$, p.o. of $2 \%$ Tween 20 in normal saline). $F(6,36)=$
14.7; $\mathrm{p}<0.05$. The fractions $\mathrm{VUH}$ and VUB as shown in Figures 15 and 17 respectively, caused a reduction in the horizontal locomotor activity at higher doses in mice $F(6,28)=4.1 ; p<0.05 ; F(6,28)=14.1 ; p<0.0001$. The fraction VUE induced dose dependent reduction in the locomotor activity (Figure 16) in all doses. In contrast, the VUA showed progressive increase in grooming activity from 100 to $800 \mathrm{mg} / \mathrm{kg}$ (Figure 18). $F(6,27)=3.1 ; p<0.05$.

Likely mechanisms of action of inhibitory effects induced by extract and ethylacetate fraction effect of picrotoxin on novelty induced locomotor activity (NIL) of VUM and VUE in mice

Picrotoxin (administered in mice 15 minutes before the 


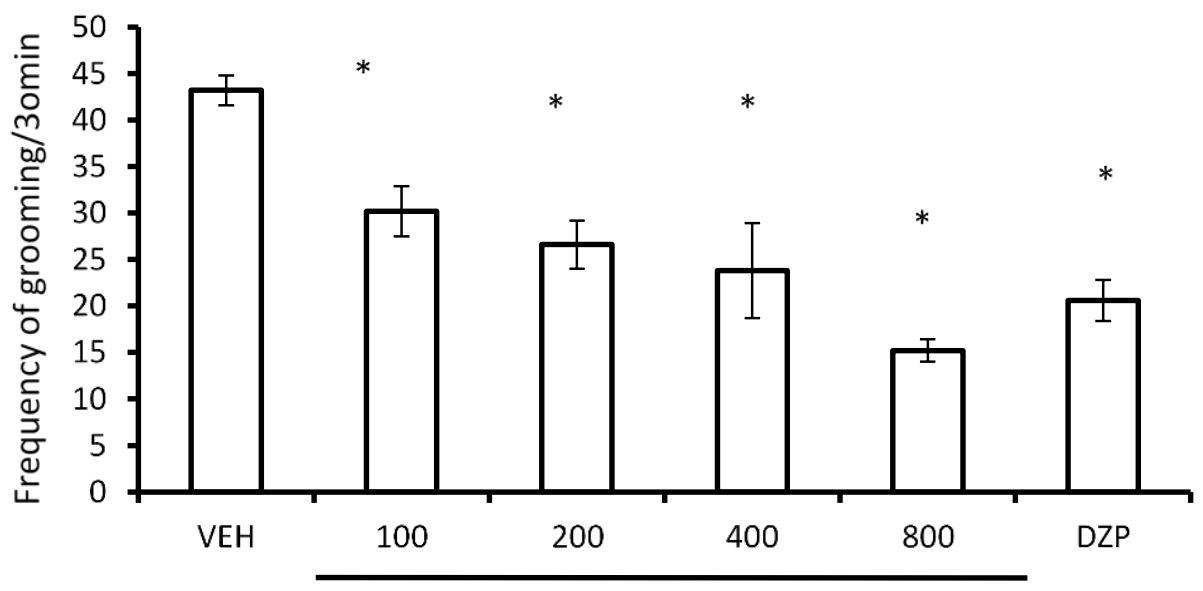

VUB (mg/kg, p.o.)

Figure 12. Effect of VUB on novelty-induced grooming. The results are expressed as mean \pm S.E.M, $(n=5)$. * significant $p<0.05$ compared to VEH.

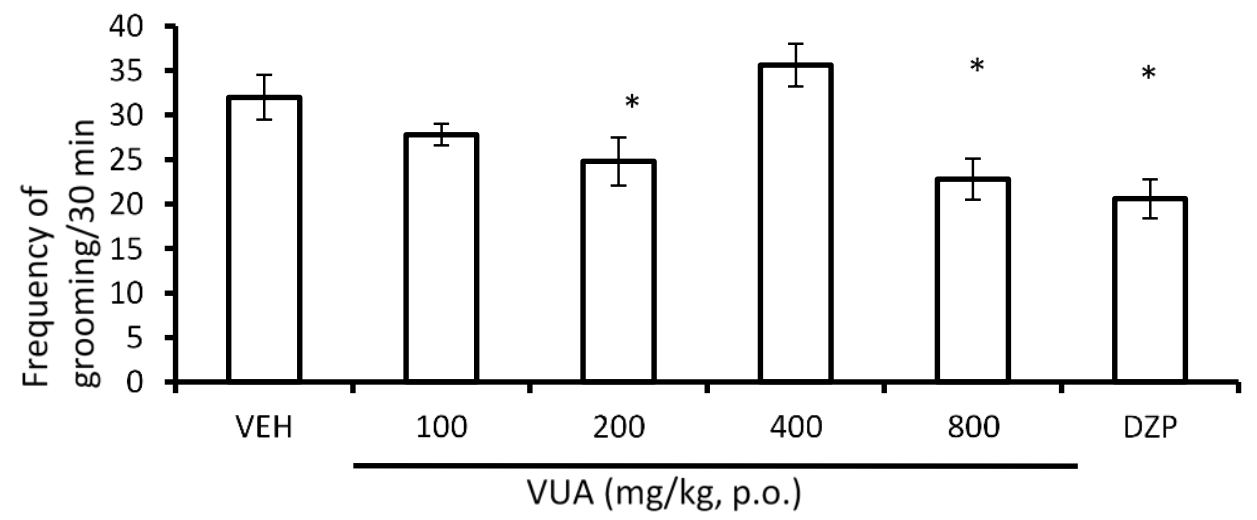

Figure 13. Effect of VUA on novelty-induced grooming. The results are expressed as mean \pm S.E.M, $(n=5)$. *significant $P<0.05$ compared to VEH.

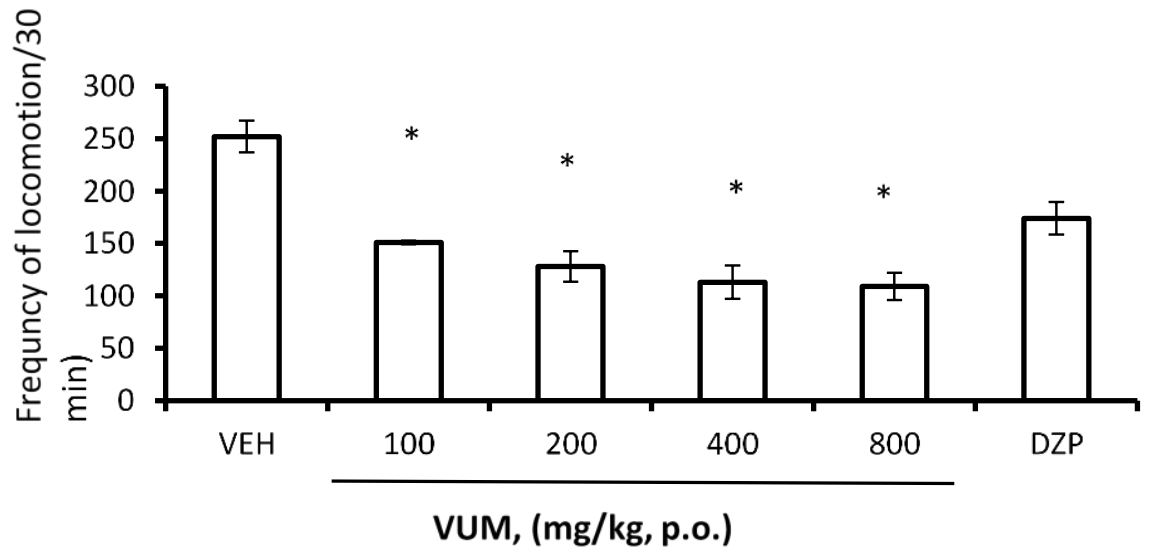

Figure 14. Effect of VUM on novelty-induced horizontal locomotion. Each bar is expressed as mean \pm S.E.M, $(n=5)$. "significant $p<0.05$ compared to VEH. 


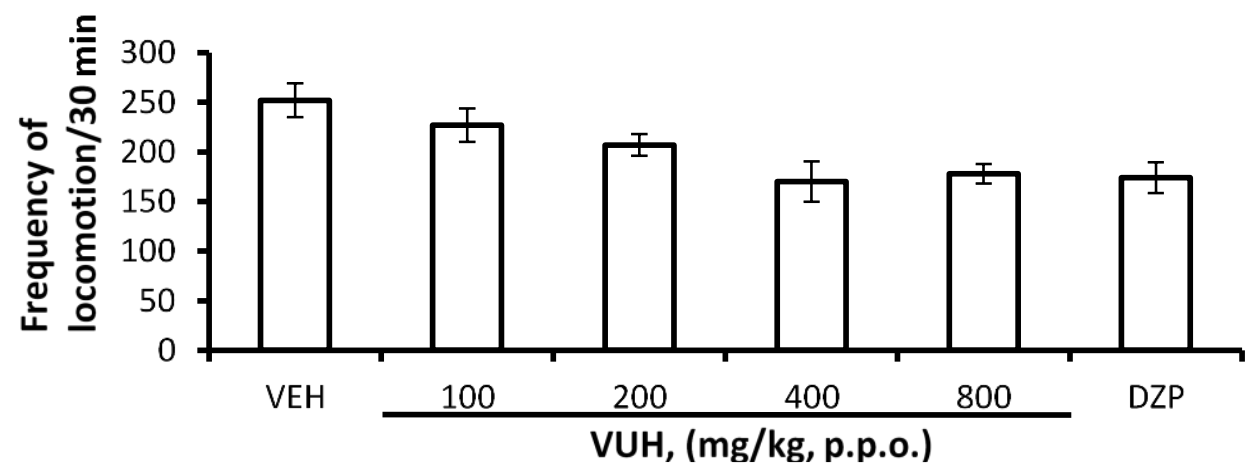

Figure 15. Effect of VUH on novelty-induced horizontal locomotion. Each bar is expressed as mean \pm S.E.M, $(n=5)$. ${ }^{*}$ significant $p<0.05$ compared VEH. $F(6,28)=4.1, p<0.05$.

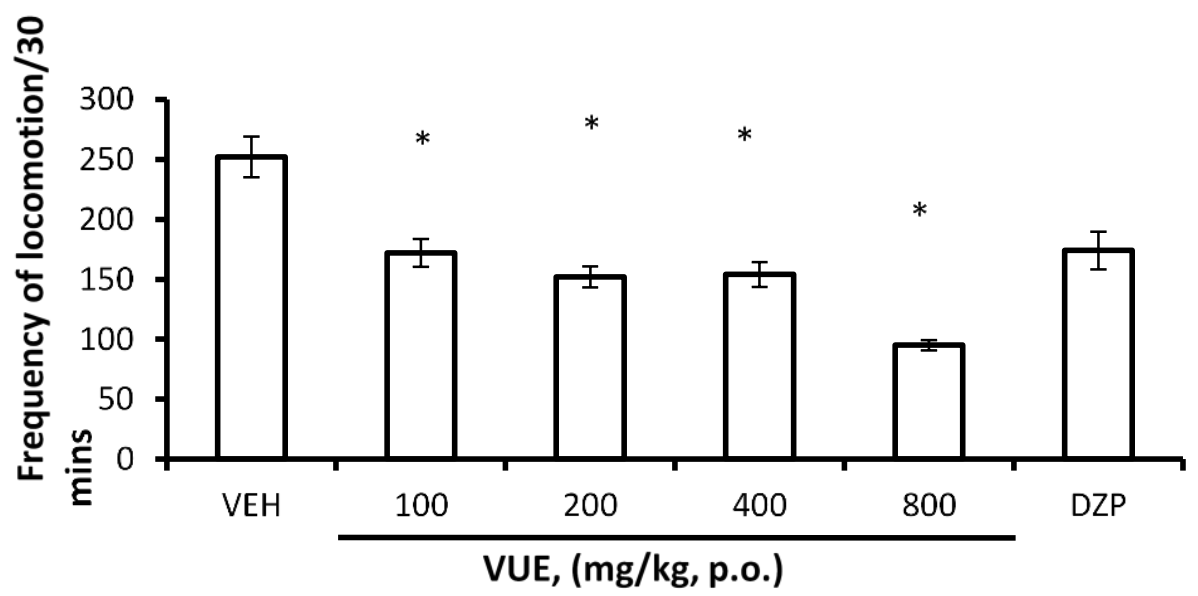

Figure 16. Effect of VUE on novelty-induced horizontal locomotion. Each bar is expressed as mean \pm S.E.M, $(n=5)$. ${ }^{*}$ significant $p<0.05$ compared to VEH.

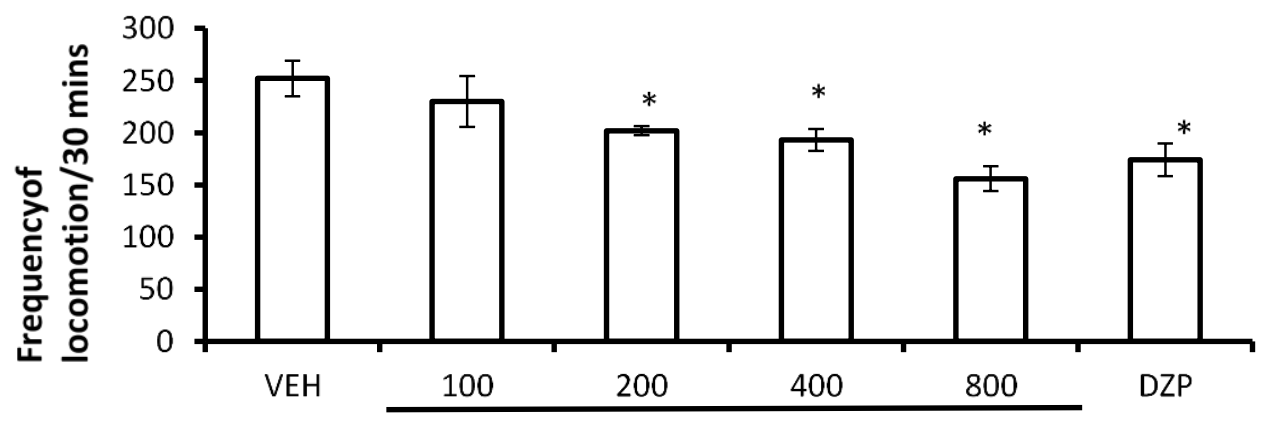

VUB. (mg/kg. p.o.)

Figure 17. Effect of VUB on novelty-induced horizontal locomotion. Each bar is expressed as mean \pm S.E.M, $(n=5)$. *significant $p<0.05$ compared to VEH.

extract) reversed the reduction in locomotor activity induced by VUM and VUE. The reversal was significantly
$(F(4,20)=13.2 ; p<0.05)$ different from the locomotor activity induced by the extract and fraction alone (Figure 19). 


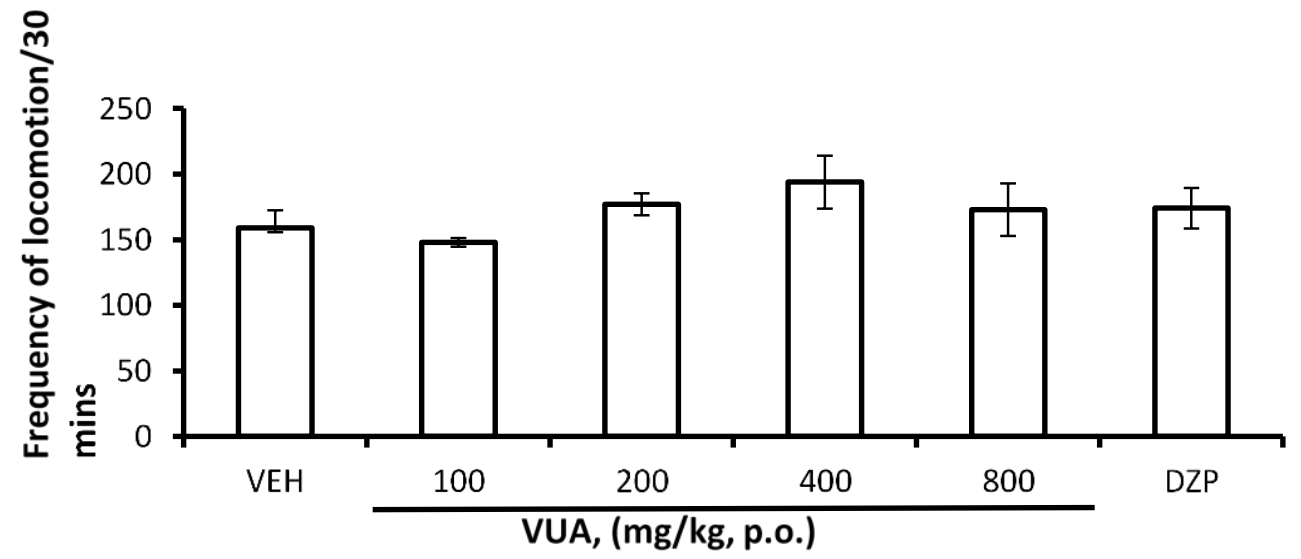

Figure 18. Effect of VUA on novelty induced locomotion. Each bar is expressed as mean \pm S.E.M, $(n=5)$. There is progressive increase in locomotor activity from VUA 100 to VUA 400.

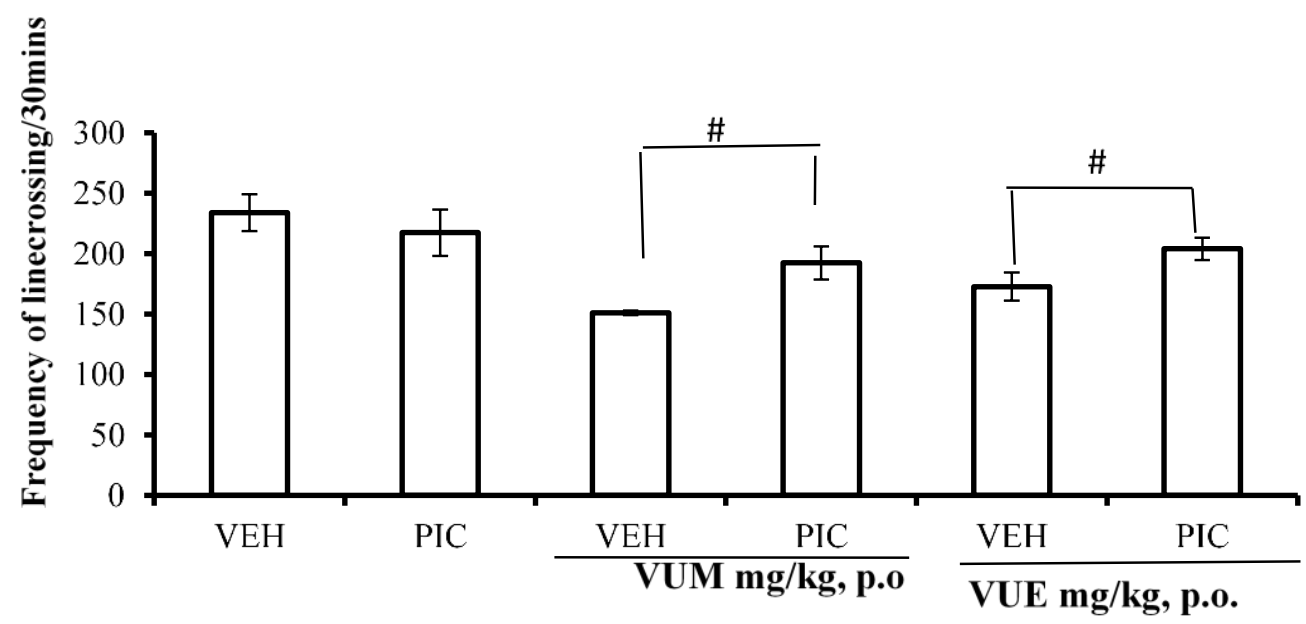

Figure 19. Effect of picrotoxin on horizontal locomotion induced by VUM and VUE. Each bar is expressed as mean \pm S.E.M, $(n=5)$. One way ANOVA revealed significant difference between VUM 100 and VUM + pic as well as between VUE 100 and VUE + pic. picrotoxin, $(1 \mathrm{mg} / \mathrm{kg}$, i.p.); \#significant $p<0.05$ : antagonist versus treatment alone.

\section{Effect of yohimbine and cyproheptadine on novelty induced locomotor activity (NIL) of VUM and VUE in mice}

Yohimbine and cyproheptadine potentiated the reduction in the locomotor activity induced by VUM and VUE (Figures 20 and 21 when mice was pretreated with the antagonist. $F(4,20)=22.2 ; p<0.05$.

\section{Effect of extract and fractions on pentobarbital- induced sleeping time (PIST) and sleep latency in mice}

The sedative potentials of the methanol extract of $V$. unguiculata and its fractions at various doses were evaluated using pentobarbital-induced sleep latency and sleeping time. The methanol extract reduced the sleep latency in all the doses $(100,200$ and 400$) \mathrm{mg} / \mathrm{kg}$ (Figure 22) compared with the control $(F(4,20)=12.6 ; p<0-05)$. VUM produced dose dependent increase in the sleeping time (Figure 23) and each dosage group $(n=5)$ is significantly different from the control $(F(4,20)=13.1)$. VUH on the other hand caused an increase in the sleep latency in all the groups compared with control except diazepam group which caused significant decrease from the control but produced significant prolongation of the sleeping time only at $100 \mathrm{mg} / \mathrm{kg}$ (Figures 24 and 25). In another experiment, one way ANOVA revealed that VUE showed significant decrease in the sleep latency in all the groups (Figure 26) $(n=5) . F(4,20)=12.8$. The sleeping time was progressively prolonged and was significantly 


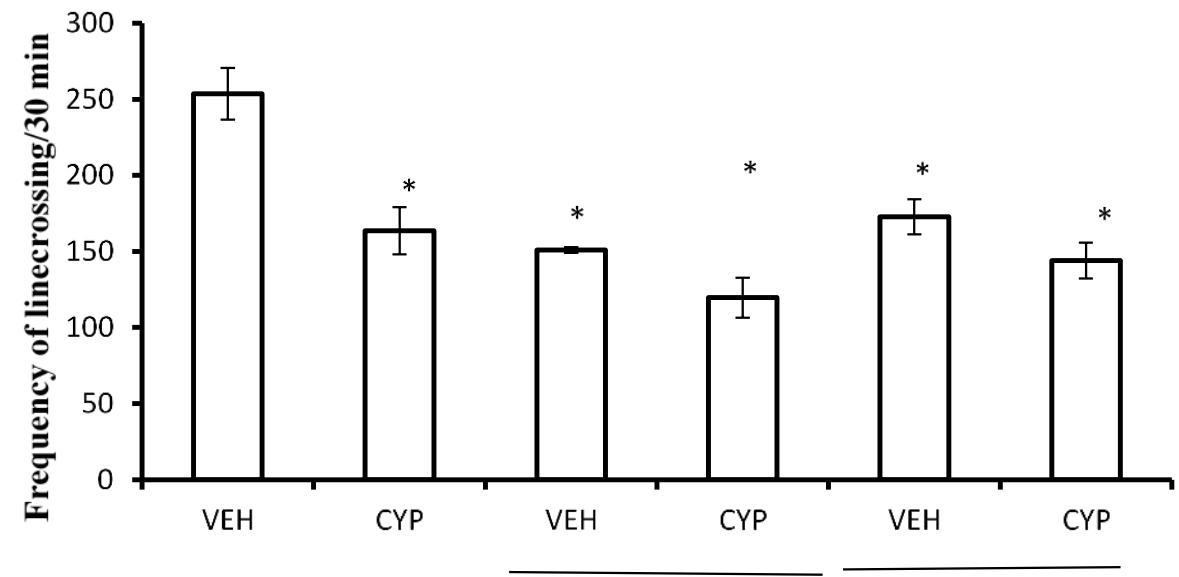

VUM, mg/kg, p.o.

Figure 20. Effect of cyproheptadine on locomotion induced by VUM and VUE. Each bar is expressed as mean \pm S.E.M, $(n=5)$. One way ANOVA revealed no significant difference between VUM 100 and VUM + CYP as well as between VUE 100 and VUE + CYP F $(4,20)=13.2$; VUM: CYP: cyproheptadine (0.5 mg/kg, i.p.); ${ }^{*} p<0.05$ significant compared to VEH.

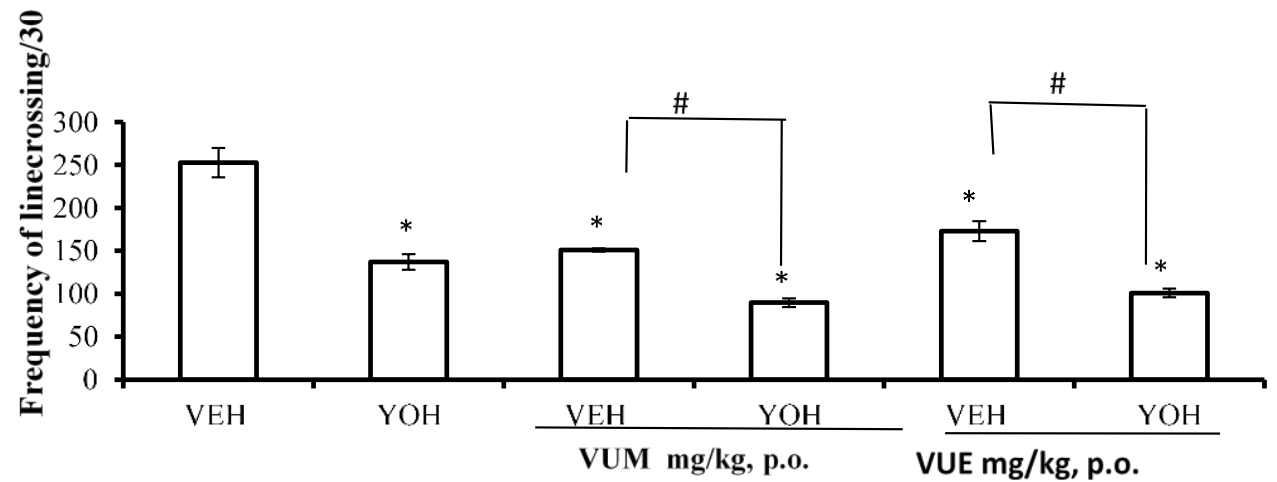

Figure 21. Effect of yohimbine on horizontal locomotion induced by VUM and VUE. Each bar is expressed as mean \pm S.E.M, $(n=5)$. One way ANOVA revealed significant difference between VUM 100 and VUM + YOH as well as between VUE 100 and VUE + YOH F $(4,20)=$ 22.2, $\mathrm{p}<0.05$; $\mathrm{YOH}$ : yohimbine ( $1 \mathrm{mg} / \mathrm{kg}$, i.p.); ${ }^{*}$ significant $\mathrm{P}<0.05$ compared to $\mathrm{VEH}$; \#significant difference: antagonist versus treatment alone.

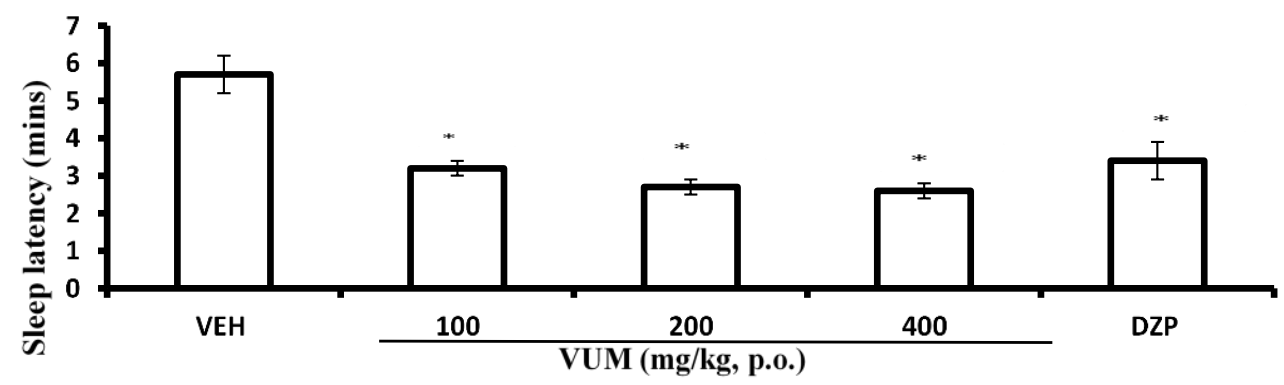

Figure 22. Effect of methanol extract on sleep latency in pentobarbital induced sleep in mice. Each bar represents mean \pm S.E.M, $(n=5)$. There was significant difference between VEH control group compared with the other groups. pentobarbital (30 mg/kg, i.p.); *significant $\mathrm{p}<0.05$ compared to VEH. 


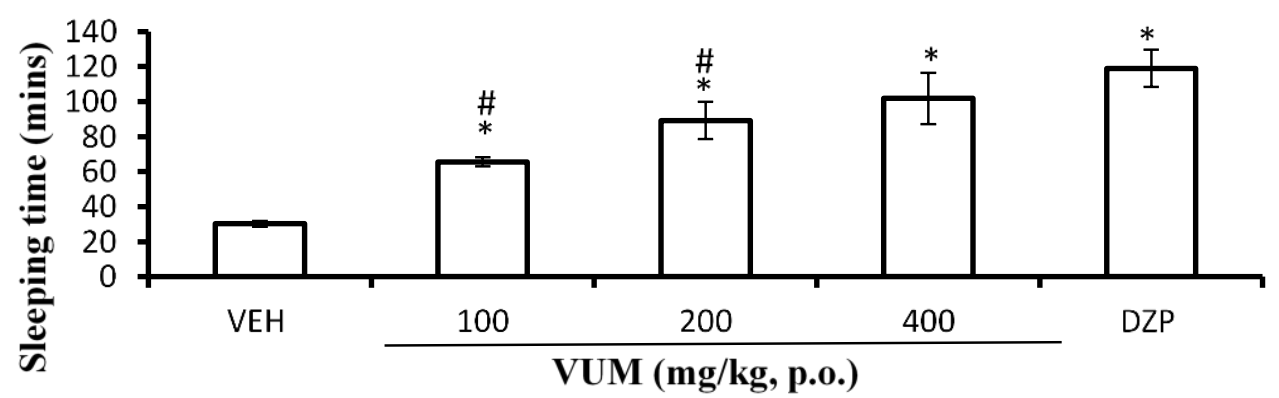

Figure 23. Effect of methanol extract on pentobarbital induced sleeping time. Each bar represents mean \pm S.E.M, $(n=5)$. The prolongation of sleeping time was dose dependent; DZP: diazepam (2 mg/kg, i.p.); pentobarbital (30 mg/kg, i,p.); *significant $p<0.05$ compared to VEH; "significant compared to DZP.

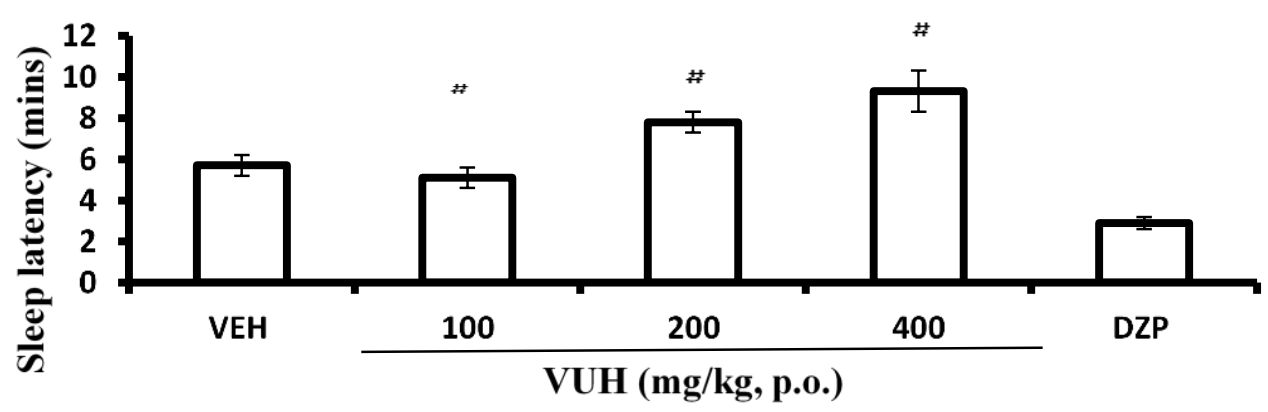

Figure 24. Effect of fraction on hexane onset of sleep. Each bar represents mean \pm S.E.M, $(n=5)$. One way ANOVA showed an increase in sleep latency in VUH 200 and VUH 400. VUH: DZP: diazepam (2 mg/kg, i.p.); Pentobarbital (30 mg/kg, i.p.); *significant $\mathrm{P}<0.05$ compared to VEH; "significant compared to DZP.

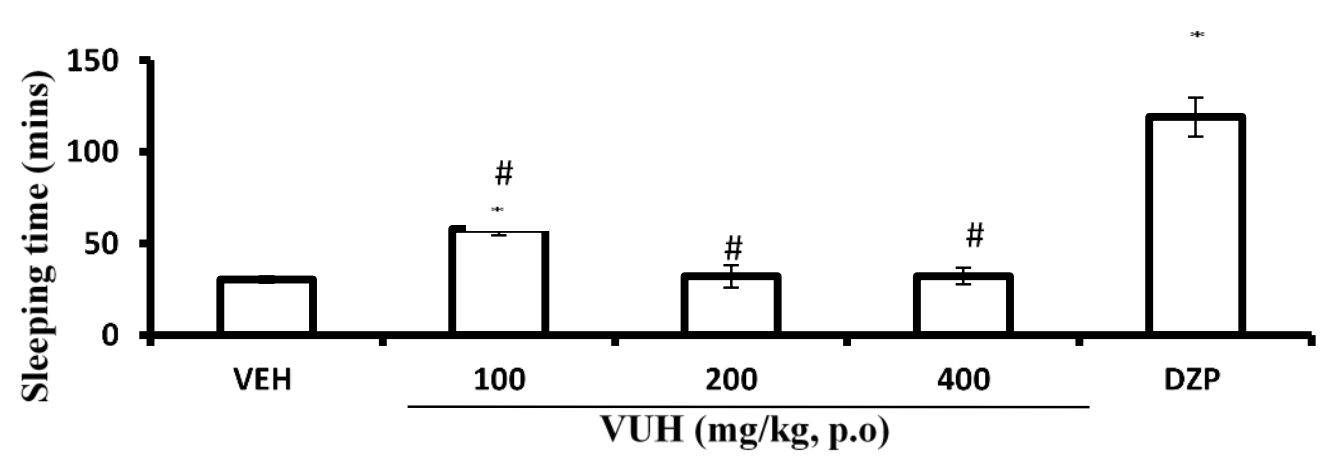

Figure 25. Effect of $n$-hexane fraction on sleeping time. Each bar represents mean \pm S.E.M, (n $=5)$. One way ANOVA showed an increase in sleeping time in $\operatorname{VUH} 100$ only. $F(4,20)=15.7$; DZP: diazepam (2 mg/kg, i.p.); pentobarbital (30 mg/kg, i.p.); *significant $p<0.05$ compared to VEH; \#significant compared to DZP.

different from the control (Figure 27). $F(4,20)=32.2$; $\mathrm{p}<0.05$. In the VUB test, the fraction at various doses did not cause any change in the sleep latency in mice (Figure 28) $(F(4.20)=10.6)$ but VUB $(200,400) \mathrm{mg} / \mathrm{kg}$ of the fraction (Figure 29) and DZP group prolong the sleeping time and the prolongation is significant compared to control $(F(4,20)=15.9 ; p<0.05)$. The $100 \mathrm{mg} / \mathrm{kg}$ of VUA fraction did not produce any change compared with the control in sleep latency but the prolongation in sleep latency induced by 200 and $400 \mathrm{mg} / \mathrm{kg}$ was significant 


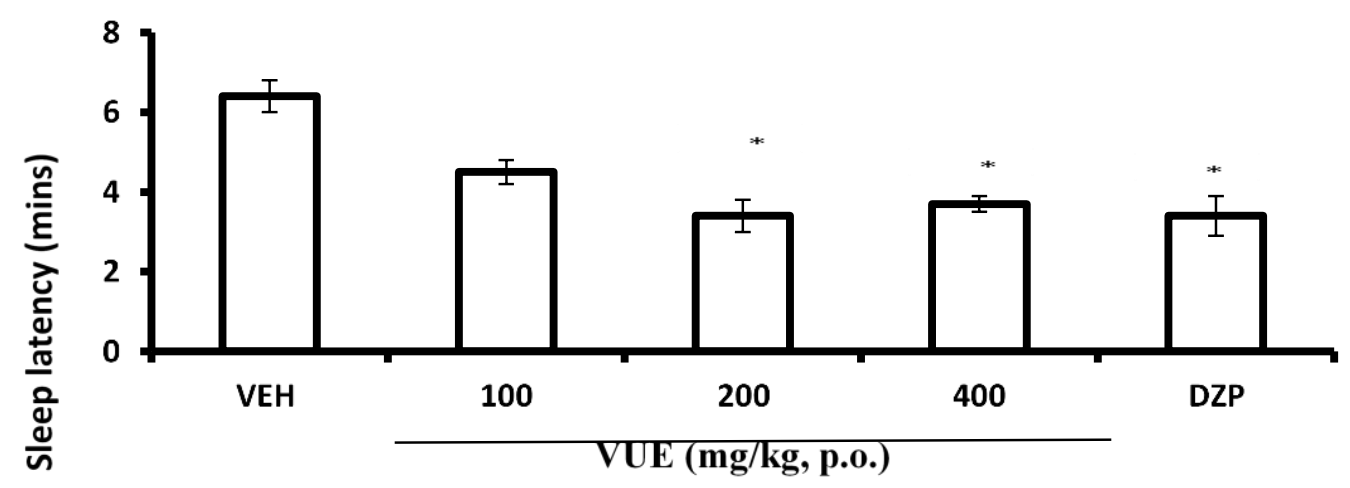

Figure 26. Effect of ethyl acetate fraction on onset of sleep. Each bar represents mean \pm S.E.M, $(n=5)$. One way ANOVA showed significant decrease in sleep latency in all the groups compared with the control. DZP: diazepam (2 mg/kg, i.p.); Pentobarbital (30 mg/kg, i.p.); ${ }^{*}$ significant p $<0.05$ compared to VEH.

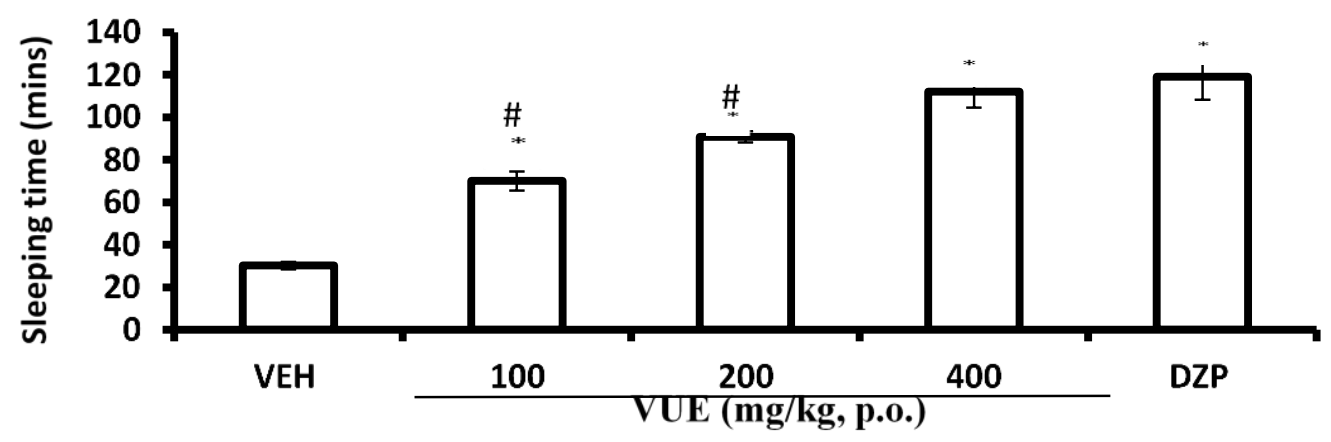

Figure 27. Effect of ethyl acetate fraction on sleeping time. Each bar represents mean \pm S.E.M, $(n=5)$. One way ANOVA showed significant prolongation in sleeping time in all the groups compared with the control. DZP: diazepam (2 mg/kg, i.p.) Pentobarbital (30 mg/kg, i.p.) *significant $\mathrm{p}<0.05$ compared to VEH; "significant compared to DZP.

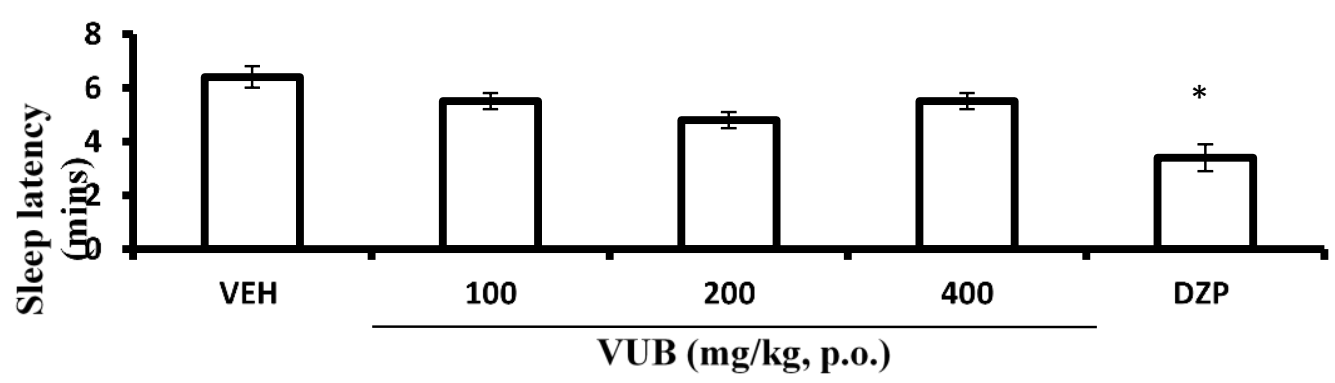

Figure 28. Effect of butanol fraction on onset of sleep. Each bar represents mean \pm S.E.M, $(n=$ 5). One way ANOVA showed decrease in sleep latency in all the groups compared with the control but only DZP was found to be significant. DZP: diazepam (2 mg/kg, i.p.); Pentobarbital (30 mg/kg, i.p.); *significant $\mathrm{p}<0.05$ compared to VEH.

$(F(4,20)=12.4, p<0.05)$ compared to control. VUA prolong the sleeping time at $100 \mathrm{mg} / \mathrm{kg}$ while there was no effect at VUA 200 and $400 \mathrm{mg} / \mathrm{kg}(\mathrm{F}(4,20)=39.2 ; \mathrm{p}<0.05)$
(Figures 30 and 31). The likely mechanism of action of hypnosis induced by the extract and fraction of this plant was determined by administration of flumazenil 15 minutes 


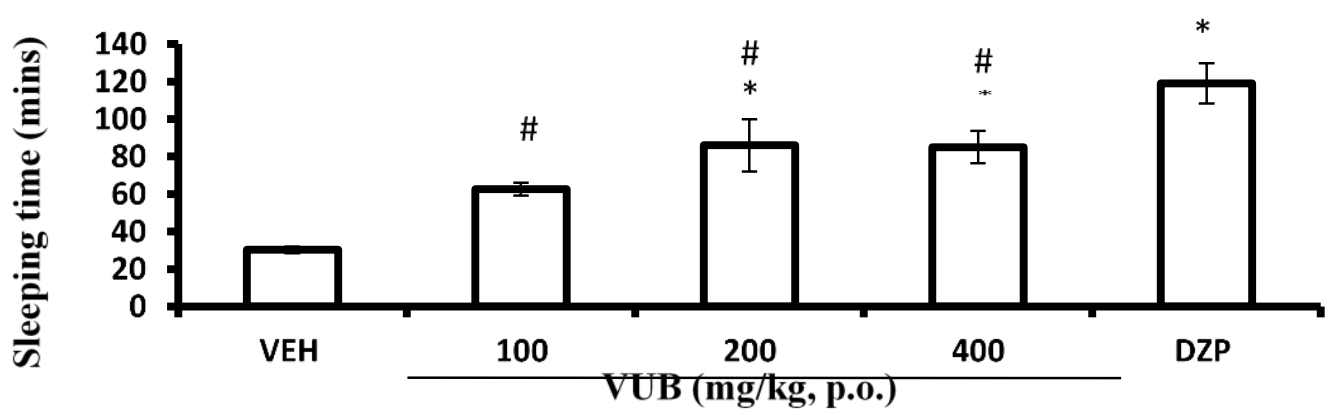

Figure 29. Effect of butanol fraction on sleeping time. Each bar represents mean \pm S.E.M, $(n=5)$. There is significant prolongation in sleeping time in the group of VUB 200, VUB 400 and DZP compared with the control. $F(4,20)=15.9$; Pentobarbital $(30 \mathrm{mg} / \mathrm{kg}$, i.p.); *significant $p<0.05$ compared to VEH; " significant compared to DZP.

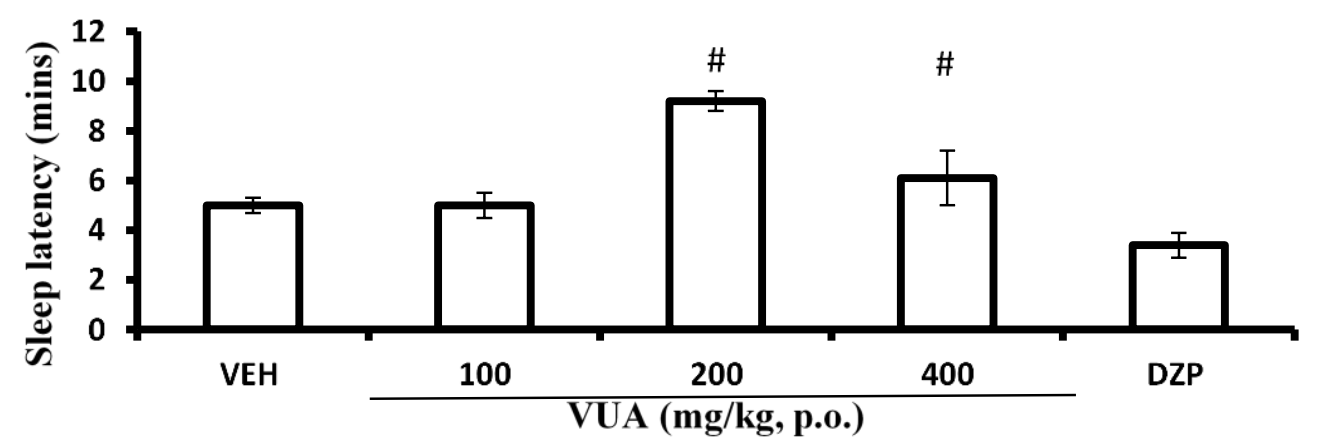

Figure 30. Effect of aqueous fraction on onset of sleep. Each bar represents mean \pm S.E.M, $(n=5)$. One way ANOVA showed increase in sleep latency in the groups VUA 200 and VUA 400 compared with the control. DZP: diazepam (2 mg/kg, i.p.); Pentobarbital (30 mg/kg, i.p.); *significant $p<0.05$ compared to VEH; " significant compared to DZP.

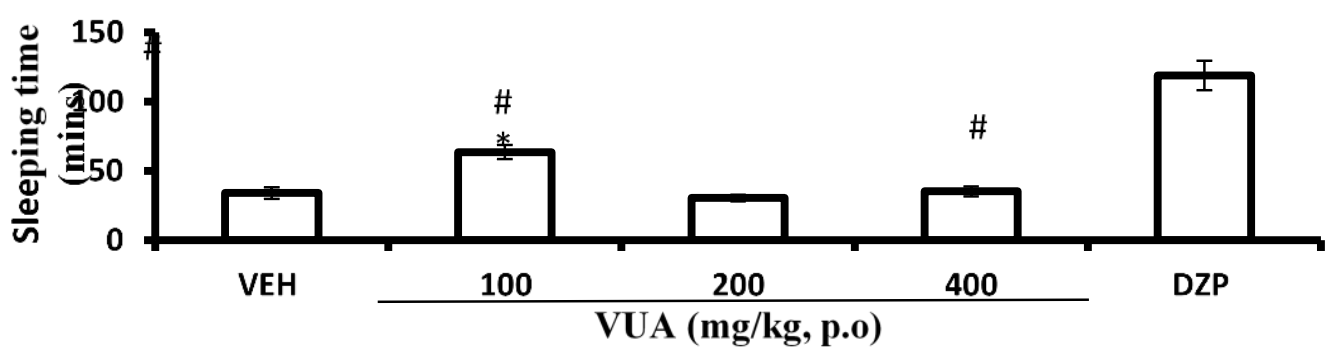

Figure 31. Effect of aqueous fraction on pentobarbital induced sleeping time. Each bar represents mean \pm S.E.M, $(n=5)$. One way ANOVA showed increase in sleeping time VUA 100 and DZP groups. DZP: diazepam (2 mg/kg, i.p.); Pentobarbital (30 mg/kg, i.p.); *significant $p<0.05$ compared to VEH; " $s$ significant compared to DZP.

(i.p.) prior to the administration of VUM and VUE (p.o.), the result showed that flumazenil reversed the reduction of the sleep latency induced by the extract and fraction (Figure 32). In the same vein, flumazenil exerted the reversal action on the sleeping time induced by VUM and VUE (Figure 33) $(F(4,20)=20.3 ; p<0.05$.

\section{DISCUSSION}

Novelty-induced behavior models have been widely used to assess and to screen medicinal agents that modified behaviours (van der Staay et al., 2009). These tests (rearing, grooming and locomotion) provide a unique 


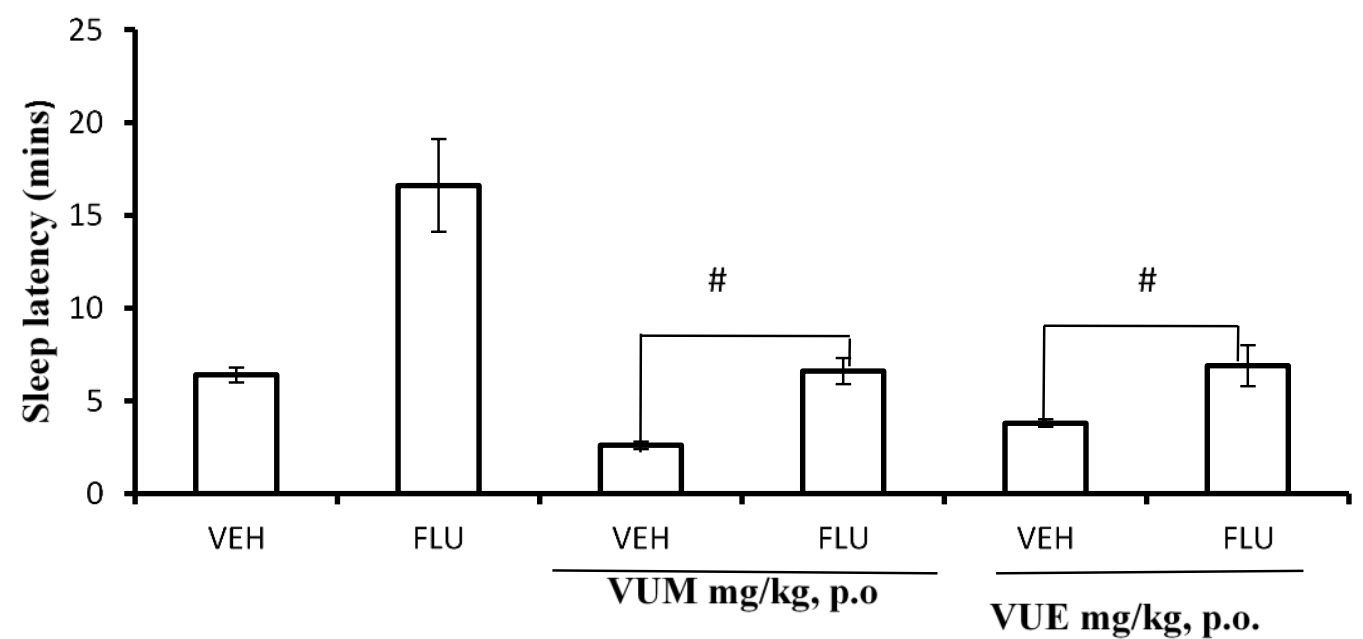

Figure 32. Effect of flumazenil on onset of sleep. Each bar represents mean \pm S.E.M, $(n=5)$. One way ANOVA showed reversal in the reduction of onset of sleep VUM and VUE. VUM (400 $\mathrm{mg} / \mathrm{kg}$, p.o); VUE (400 mg/kg, p.o.); Pentobarbital (30 mg/kg, i,p,); FLU: flumazenil (3 mg/kg, i.p.); \#significant $p<0.05$ : antagonist versus treatment alone.

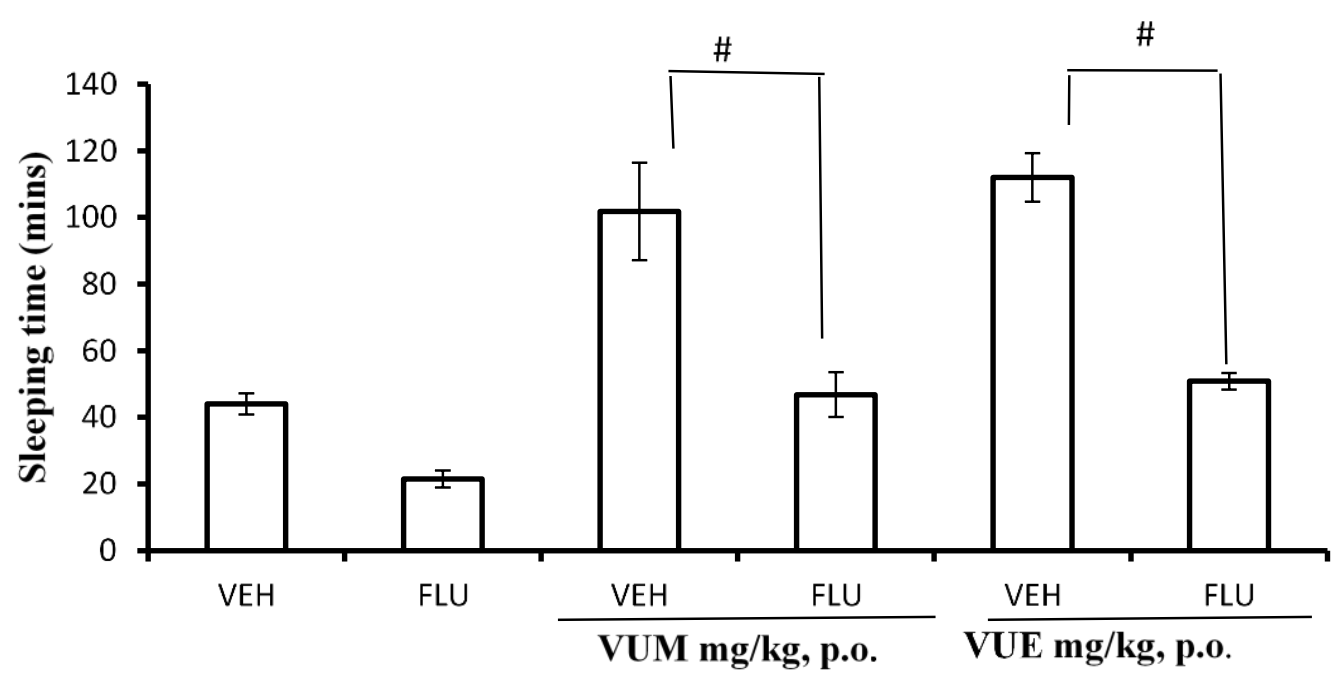

Figure 33. Effect of flumazenil on duration of sleep. Each bar represents mean \pm S.E.M, $(n=5)$. One way ANOVA showed reversal in the reduction in the sleeping time of VUM $(400 \mathrm{mg} / \mathrm{kg})$ and VUE (400 mg/kg). FLU: Flumazenil (3 mg/kg, i.p.); Pentobarbital (30 mg/kg, i.p.); \#significant $\mathrm{p}<0.05$ : antagonist versus treatment alone.

opportunity to systematically assess the central nervous system effect of the extract and the fractions on mice when exposed to a novel environment (Lever et al., 2006). These behavioural tests can be considered the output of interaction between inhibitory and stimulatory synaptic mechanisms that occur in the central nervous system (Hanell and Marklund, 2014). Rearing, grooming and locomotion are measure of central nervous excitation (Ajayi and Ukponmwan, 1994). These behaviours may be mediated via multiple neurotransmitters and receptor pathways, such as gamma-aminobutyric acid (GABA), cholinergic, adrenergic, opioids, serotonin, glutamate and dopamine receptors (Walting, 1998). The agents that cause increase in rearing activity in rodents when exposed to novel environment is said to have a stimulatory effect, while those that cause a decrease in rearing effect are said to possess inhibitory effect. The study showed that the extract and fractions (VUH and VUE) caused dose- 
dependent decrease in rearing, grooming and locomotion demonstrating their inhibitory effect. The dose-dependent decrease induced by the extract and fractions were statistically significant compared to the control. The inhibitory effect was more pronounced with the administration of the methanol extract (VUM) and ethylacetate fraction (VUE) when compared to other fractions. The aqueous fraction (VUA)on the other hand, induced a significant dose-dependent increase in the behavioural parameters (rearing, grooming and locomotion) indicating induced-stimulatory effect of the fraction. This finding is similar to the work of Akinpelu et al. (2017). The result suggests that this fraction (VUA) may contain some active principles that exerted the stimulatory effect in mice as observed in the test.

The possible mechanism of the inhibitory neurobehavioural effect of the plant was investigated using yohimbine ( $\alpha_{2}$-adrenergic antagonist), picrotoxin (GABA antagonist) and cyproheptadine (5-HT antagonist). A sub-convulsive dose of picrotoxin has been used to elucidate the mechanism of action of inhibitory/excitatory effect at the vertebrate and invertebrate central synapses (Johnston, 2013). Picrotoxin reversed the novelty-induced rearing (NIR) in mice (VUM and VUE). This suggests that the induction of NIR may be mediated via GABAergic transmission. The blockade of ionotropic ion channel receptors $\left(G A B A_{A}\right)$ by picrotoxin may be responsible for this reversal effect observed in the test. On the other hand, both the yohimbine and cyproheptadine potentiated the NIR. Yohimbine has been reported to act as agonist at 5$\mathrm{HT}_{1 \mathrm{~A}}$ receptor while it demonstrated antagonism at alpha 2-adrenergic receptor as well as $5-\mathrm{HT}_{1 \mathrm{~B}}, 5-\mathrm{HT}_{1 \mathrm{D}}$ and dopamine $\left(D_{2}\right)$ receptors (Millan et al., 2000). Activation of $5-\mathrm{HT}_{1 \mathrm{~A}}$ receptor in all neurons in CNS is generally inhibitory and acts by reducing neuronal firing (Barnes and Sharp, 1999). Haberzettl et al. (2014) reported that stimulation of $5-\mathrm{HT}_{1 \mathrm{~A}}$ by agonist induced pilo-erection, tremor and decrease in rearing. The potentiation of inhibition of NIR induced by extract and fractions by yohimbine may be due to its agonist action at this receptor. The potentiation of locomotor activity induced by yohimbine may suggest the involvement of hippocampal alpha 2-adrenergic or serotonergic receptors. The further decrease in horizontal locomotion may be due to antagonism effect of yohimbine at $5-\mathrm{HT} 1_{\mathrm{B}}$ and $5-\mathrm{HT} 1_{\mathrm{D}}$ receptors. This finding is similar to the study conducted by Nishio et al. (2003) in which yohimbine dose-dependently decreased the ambulatory hyperactivities induced by methamphetamine (METH $2 \mathrm{mg} / \mathrm{kg}$ ) in mice.

The sleep latency is the time it takes the mouse to lose righting reflex while the sleeping time is the time the mouse regains the righting reflex (Fisher et al., 2012). In the pentobarbital-induced sleeping hypnosis test, the extract (VUM) and the fractions produced significant dose dependent reduction in the latency of sleep and increase the duration of sleep in mice. The difference in sleep latency and sleeping time is more pronounced in VUM and VUE as compared to the negative control. This may indicate that the VUM and VUE contain more active principles that is responsible for the sleeping time induced in mice. The extract at $400 \mathrm{mg} / \mathrm{kg}$ induced a sleeping time that is comparable to the standard drug (diazepam, $2 \mathrm{mg} / \mathrm{kg}$, i.p.). There was a significant prolongation in sleeping time at higher doses compared to vehicle treated mice. In another experiment involving VUA, there is an increase in the sleep latency compared with the negative control whereas; there is no appreciable change in the sleeping time. The possible mechanism of action of hypnotic effect was evaluated using flumazenil (GABA antagonist). The reduction in sleep latency as well as the prolongation of sleeping time induced by VUM and VUE were reversed by this antagonist. The reversal of both sleep latency and sleeping time were significantly different from control. The result suggests that the hypnotic effect induced by the VUM and VUE may be mediated through GABAergic neurotransmission.

\section{Conclusion}

The result of this present study showed that methanol extract of $V$. unguiculata $(L)$ Walp susp dekindtiana and its fractions (VUH and VUE) exhibited central inhibitory effects in mice. The extract and these fractions have shown a demonstrable hypnotic effect in mice. Further purification guided studies will be required to identify and isolate the active principles responsible for these effects.

\section{CONFLICT OF INTEREST}

The authors declare that they have no conflict of interest.

\section{REFERENCES}

Aderibigbe, A. O., Iwalewa, E. O., Adesina, S. K., \& Agboola, O. I. (2010). Studies of behavioural and neural mechanisms of aridanin isolated from Tetrapleura tetraptera in mice. International Journal of Pharmacology, 6(4), 480-486.

Aduema, W., Azunna, U., \& Agbai, J. U. (2017). Analgesic activity of vigna unguiculata in CD-1 mice following formalin administration. Continental Journal of Biological Sciences, 10(2), $1-9$

Ajayi, A. A., \& Ukponmwan, O. E. (1994). Evidence of Angiotensin II and endogenous opioid modulation of noveltyinduced rearing in the rat. African Journal of Medicine and Medical Sciences, 23, 287-290.

Akinpelu, L. A., Adegbuyi, T. A., Agboola, S. S., Olaonipekun, J. K., Olawuni, I. J., Adegoke, M. A., Oyemitan, I. A., \& Olayiwola, G. (2017). Antidepressant activity and mechanism of aqueous extract of Vigna unguiculata ssp.dekindtiana (L.) Walp dried aerial part in mice. International Journal of Neuroscience and Behavioral Science, 5(1), 7-18.

Ayan, I., Mut, H., Basaran, N., Acar, Z., \& Ascl, O. O. (2012). Forage potentials of cowpea (Vigna unguiculata L. Walp). Turkish Journal of Field crops, 17(2), 135-138.

Barnes, N. M., \& Sharp, T. (1999). A review of central 5-HT receptors and their function. Neuropharmacology, 38(8), 1083-1152. 
Erden, B. F., Ulak, G., Yildiran, G., \& Gacar, N. (1997). The effect of 7-nitro indazole on pentobarbital-induced sleep in mice. Pharmacological research, 36(4), 265-267.

Falodun, A. T., Ajayi, C. O., Obuotor, E. M., Adepiti, A. O., Akanmu, M. A. and Elujoba, A. A. (2015). Antiplasmodial properties, toxicity and novelty-induced behavior of a formulation from Picralima nitida and Alstonia boonei. European Journal of Medicinal Plants, 8(2), 112-120.

Fery, F. L., (2002). New opportunities in Vigna. In: Janick. J., \& Whipkey A. (eds.), Trends in new crops and new uses. ASHS press, Alexandria V. A. Pp. 424-428.

Fisher, S. P., Godinho, S. I. H., Pothecary, C. A., Hankins, M. W., Foster, R. G., \& Peirson, S. N. (2012). Rapid assessment of sleep/wake behaviour in mice. Journal Biological Rhythms, 27(1), 48-58.

Gangarao, B., Anjana Male, Ch. K. V. L. S. N., Hari Priya, T., Venna, N. M., Reeshma, S. K. (2011). A phytopharmacological review on vigna species. Pharmanest an International Journal of Advances in Pharmaceutical Sciences, 2(1), 62-67.

Gupta, U. K., Das, S., Aman, S., \& Nayak, A. (2016). Pharmacological activities of Vigna unguiculata- a review. World Journal of Pharmaceutical Research, 5(10), 337-345.

Haberzettl, R., Fink, H., \& Bert, B. (2014). Role of 5-HT1 A- and 5$\mathrm{HT} 2_{\mathrm{A}}$ receptors for the murine model of the serotonin syndrome. Journal of Pharmacological and Toxicological Methods, 70(2), 129-133.

Hanell, A., \& Marklund, N. (2014). Structured evaluation of rodent behavioral tests used in drug discovery research. Frontiers in Behavioral Neuroscience, 8(article 252), 1-13.

Hasan, S. M. R., Hossain, M., Akter, R., Mariam, J., Hoque Mazumder, E., \& Shafiqur, R. (2009). Sedative and anxiolytic effects of different fractions of the Commelinaben ghalensis Linn. Drug Discovery Therapy; 3(5), 221-227.

Hershey, J. D., Gifford, J. J., Zizza, L. J., Pavlenko, D. A., Wagner, G. C., \& Miller, S. (2018). Effects of Various Cleaning Agents on the Performance of Mice in Behavioral Assays of Anxiety. Journal of the American Association for Laboratory Animal Science, 57(4), 335-339.

Ishyaku, M. F., \& Aliyu, H. (2013). Field evaluation of cowpea Genotypes for drought tolerance and striga resistance in the dry savanna of the North-West Nigeria. International Journal of Plant Breeding and genetics, 7(1), 47-56.

Johnston, G. A. (2013). Advantages of an antagonist: bicuculline and other GABA antagonists. British Journal of Pharmacology, 169(2), 328-336.

Kumar, K. S., Rajesh, K., Anusha, D., \& Suthakaran, R. (2014). Potentiation of phenobarbitontal-induced hypnosis by Celosia Argentea Leaves. International Journal of Medicine and Pharmaceutical Research, 2(3), 622-625.
Lever, C., Burton, S., \& O'Keefe, J. (2006). Rearing on hind legs, environmental novelty, and the hippocampal formation. Reviews in the Neurosciences, 17(1-2), 111-134.

Lush, W. M., Evans, L. T., \& Wien, H. C. (1980). Environmental adaptation of wild and domesticated cowpeas (Vigna unguiculata (L.) Walp.). Field crops research, 3, 173-187.

Millan, M. J., Newman-Tancredi, A., Audinot, A., Cussac, D., Lejeune, F., Nicolas, J. P., Coge, F., Galizzi, J. P., Boutin, J. A., Rivet, J. M., Dekevne, A., \& Gobert, A. (2000). Agonist and antagonist actions of yohimbine as compared to fluparoxan at alpha(2)-adrenergic receptors $(A R)$, serotonin $(5-H T)\left(1_{A}\right), 5-$ $\mathrm{HT}(1 \mathrm{~B}), 5-\mathrm{HT}(1 \mathrm{D})$ and dopamine $\mathrm{D}(2)$ and $\mathrm{D}(3)$ receptors. Significance for the modulation of fronto-cortica monoaminergic transmission and depressive states. Synape, 35(2), 79-95.

Nishio, M., Kukoki, Y., \& Watanabe, Y. (2003). Role of hippocampal alpha $\left(2_{A}\right)$-adrenergic receptor in methamphetamine-induced hyper-locomotion in the mouse. Neuroscience Letters, 341(2), 156-160.

Olayiwola, G., Ukponmwan, O., \& Olawode, D. (2013). Sedative and anxiolytic effects of the extracts of the leaves of Stachytarpheta cayennensisin mice. African Journal Traditional Complementary Alternative Medicine, 10(6), 568579.

Onigbogi, O., Ajayi, A. A., \& Ukponmwan, O. E. (2000). Mechanisms of chloroquine induced body scratching behaviour in rats: Evidence of involvement of endogenous opioid peptides. Pharmacology Biochemistry Behaviour, 65(2), 333-337.

Oyekunle, O. A., Akanmu, M. A., \& Ogundeji, T. P. (2010). Evaluation of anxiolytic and novelty induced behaviours following bee-honey consumption in rats. Journal of Neuroscience and Behavioural Health, 2(4), 38-43.

Singh, B. B., Ajeigbe, H. A., Tarawali, S. A., Fernandez-Rivera, S., \& Abubakar, M. (2003). Improving the production and utilization of cowpea as food and fodder. Field Crops Research, 84(1-2), 169-177.

Stanford, S. C. (2007). The open field test: Reinventing the wheel. Journal of Psychopharmacology; 21(2), 134-144.

van der Staay, F. J., Arndt, S. S., \& Nordquist, R. E. (2009). Evaluation of animal models of neurobehavioral disorders. Behavioral and Brain Functions, 5(11), 1-23.

Walting, K. J. (1998). Overview of central nervous system receptors. The RBI Handbook of Receptor Clarification and signal transduction, 3rd edition. RBI. Natick, M. A. Pp. 2-45. 